\title{
Recent Trends in the Microwave-Assisted Synthesis of Metal Oxide Nanoparticles Supported on Carbon Nanotubes and Their Applications
}

\author{
Sarah C. Motshekga, ${ }^{1,2}$ Sreejarani K. Pillai, ${ }^{1}$ Suprakas Sinha Ray, ${ }^{1,2}$ \\ Kalala Jalama, ${ }^{2}$ and Rui. W. M. Krause ${ }^{2}$ \\ ${ }^{1}$ DST/CSIR Nanotechnology Innovation Centre, Council for Scientific and Industrial Research, Pretoria 0001, South Africa \\ ${ }^{2}$ UJ Centre of Nanomaterials Science, Department of Applied Chemisty, University of Johannesburg, Doornfontein 2028, South Africa \\ Correspondence should be addressed to Suprakas Sinha Ray, rsuprakas@csir.co.za
}

Received 16 October 2011; Accepted 30 December 2011

Academic Editor: Renyun Zhang

Copyright () 2012 Sarah C. Motshekga et al. This is an open access article distributed under the Creative Commons Attribution License, which permits unrestricted use, distribution, and reproduction in any medium, provided the original work is properly cited.

\begin{abstract}
The study of coating carbon nanotubes with metal/oxides nanoparticles is now becoming a promising and challenging area of research. To optimize the use of carbon nanotubes in various applications, it is necessary to attach functional groups or other nanostructures to their surface. The combination of the distinctive properties of carbon nanotubes and metal/oxides is expected to be applied in field emission displays, nanoelectronic devices, novel catalysts, and polymer or ceramic reinforcement. The synthesis of these composites is still largely based on conventional techniques, such as wet impregnation followed by chemical reduction of the metal nanoparticle precursors. These techniques based on thermal heating can be time consuming and often lack control of particle size and morphology. Hence, there is interest in microwave technology recently, where using microwaves represents an alternative way of power input into chemical reactions through dielectric heating. This paper covers the synthesis and applications of carbon-nanotube-coated metal/oxides nanoparticles prepared by a microwave-assisted method. The reviewed studies show that the microwave-assisted synthesis of the composites allows processes to be completed within a shorter reaction time with uniform and well-dispersed nanoparticle formation.
\end{abstract}

\section{Introduction}

The extraordinary mechanical properties and unique electrical properties of carbon nanotubes (CNTs) have stimulated extensive research in almost every research institution and industry worldwide [1]. CNTs exhibit superior thermal [2, 3], mechanical [4], and electrical properties [5-8] and are considered the most promising building block for manufacturing low-cost, high-performance nanostructured composite materials. Over the last few years increasing attention has been given to the preparation of various kinds of CNT-based composite materials to enhance the inherent properties of the matrix and optimize the use of CNTs by means of coating or filling with some foreign inorganic materials including metal/oxides [9-11]. The resultant composite materials have been envisioned to be useful for nanoscale sensors
[12-14], field emitters [15, 16], nanoelectronics [15, 17], nanotweezers [18], batteries for electrode materials [15], supercapacitors [19], hydrogen storage [20, 21], and many other unique applications.

Composites of metal/oxide nanoparticles and CNTs can be prepared by various strategies, and their preparation is still largely based on conventional techniques. Thus far, coating or deposition of CNTs with various metal nanoparticles has been developed and different methods have been used, such as solid-state reactions, capillary action, radiolysis, physical evaporation, electroless deposition, physisorption, self-assembly, and colloidal chemistry combined with electrostatic interactions or with sonication in aqueous solution [22-26]. Many of these methods typically entail multiple steps involving reflux with strong acids combined with ultrasonication that take long hours or even days followed by 
chemical reduction of the precursor metal salts. Moreover, these methods often lack good control of particle size and morphology and large amounts of materials and energy are used. Only a few reports provide simple, efficient routes for uniform dispersion and strong attachment of nanoparticles to CNT surfaces. Therefore, any new synthesis technique that helps to save time would be extremely beneficial because it would allow scientists to perform more experiments within a shorter time and testing new theories and processes could be done much faster allowing more time to expand scientific creativity [27].

Recently, a microwave-assisted method has been widely applied in chemical reactions and synthesis of nanomaterials $[11,28]$. Research has shown the method to be an attractive choice to promote reactions and is energy effective heating compared to conventional heat conduction methods (such as an oil bath) due to the direct heating of the reaction mixture [29]. By conventional methods, the vessel is heated and this then transfers the heat by convection. Microwave heating is more efficient in terms of the energy used, produces higher temperature homogeneity, and is considerably more rapid than conventional heat sources.

Microwave heating is a transfer of electromagnetic energy to thermal energy, and is an energy conversion phenomenon rather than the heat transfer. The electric component [30] of an electromagnetic field causes heating by two main mechanisms, dipolar polarization mechanism and conduction mechanism. In polarization mechanism; for a substance to generate heat when irradiated with microwaves it must possess a dipole moment, as in water molecule. A dipole is sensitive to external electric fields and will attempt to align itself with the field by rotation. The applied field provides the energy for this rotation [31]. As molecules vainly attempt to follow the field, they collide with one another and heating in the sample is observed. High- and low-frequency radiation does not give rise to efficient heating: in the first case, the field oscillates too quickly for the molecules to respond; in the second case, the molecules follow the field so well that there is no random motion generated [32].

If two samples containing distilled water and tap water, respectively, are heated in a single mode microwave cavity at a fixed radiation power and for a fixed time, the final temperature will be higher in the tap water sample. This phenomenon is due to the second major interactions of the electric field component with the sample, the conduction mechanism. The conduction mechanism is a much stronger interaction than the dipolar mechanism with regard to the heat-generating capacity [31]. In this case, any mobile charge carriers (electrons, ions, etc.) move relatively easily through the material under the influence of the microwave's electric field. These induced currents will cause heating in the sample due to any electrical resistance. If the sample is a metallic conductor, most of the microwave energy is reflected with relatively little energy penetrating beyond a few microns into the surface. However, the surface electrons respond to the field in less than $10^{-12} \mathrm{~s}$, and colossal surface potentials (of the order of hundreds of $\mathrm{kV} \mathrm{m}^{-1}$ ) may be induced. Conduction heating itself can be demonstrated quite easily in a domestic microwave oven using materials such as copper oxide or carbon. Alternatively, if pure water is heated in a microwave oven, where the polarisation mechanism dominates, the heating rate is significantly lower than that observed when the same volume of a dilute salt solution is heated. In the latter case, both dipolar polarisation and conductive mechanisms contribute to the heating effect [32].

Microwave energy is a spectrum in the same way as visible light, infrared irradiation, and UV irradiation and is delivered directly to the material through molecular interaction with the electromagnetic field. Since microwaves can penetrate the material and supply energy, heat can be generated throughout the volume of the material resulting in volumetric heating [33]. Additionally, the method shows acceleration in reaction rate, yield improvement, short reaction time, small particle size, narrow particle size distribution, high purity materials, and enhanced physicochemical properties [34-36]. The results obtained cannot be explained by the effect of the rapid heating alone, and this has led various authors to postulate the existence of "microwave effect." Historically, "specific microwave effects" have been claimed, when the outcome of a synthesis performed using microwave heating differs from the conventionally heated counterpart carried out at the same apparent temperature [33].

Microwave effects result from material-wave interactions and due to the dipolar polarization phenomenon, the greater the polarity of a molecule (such as the solvent), the more pronounced the microwave effect when the rise in temperature [37] is considered. In terms of reactivity and kinetics, the specific effect has therefore to be considered according to the reaction mechanism and particularly with regard to how the polarity of the system is altered during the progress of the reaction. The origin of specific microwave effects can be rationalized under the Arrhenius law (1) and can result from modifications in each of the terms in this equation [38]:

$$
K=A^{-\Delta G / R T} \text {. }
$$

(i) Thus, the increase in the preexponential factor $A$, which is representative of the probability of molecular impacts. The collision efficiency can be effectively influenced by mutual orientation of polar molecules involved in the reaction. As the factor is dependent on the vibration frequency of the atoms at the reaction interface, it could be postulated that the microwave field might affect this. Calculations have also shown that the faster diffusion rates might be explained by an increase in factor $A$ with no change in activation energy [38].

(ii) Decrease in activation energy $\Delta G$ is certainly a main effect. When considering the contribution of enthalpy and entropy to the value of $\Delta G[\Delta G=\Delta H-T \Delta S]$, it may be predicted that the magnitude of the $-T \Delta S$ term would increase in a microwave-induced reaction this being more organized when compared to classical heating as a consequence of dipolar polarization [38]. Lewis et al. [39] presented experimental evidence for such an assumption after measurements of rate constants according to temperature for the unimolecular imidization of a polyamic acid ((1), Figure 1, and Table 1), where the plot demonstrates the differences between the microwave solution imidization processes and 


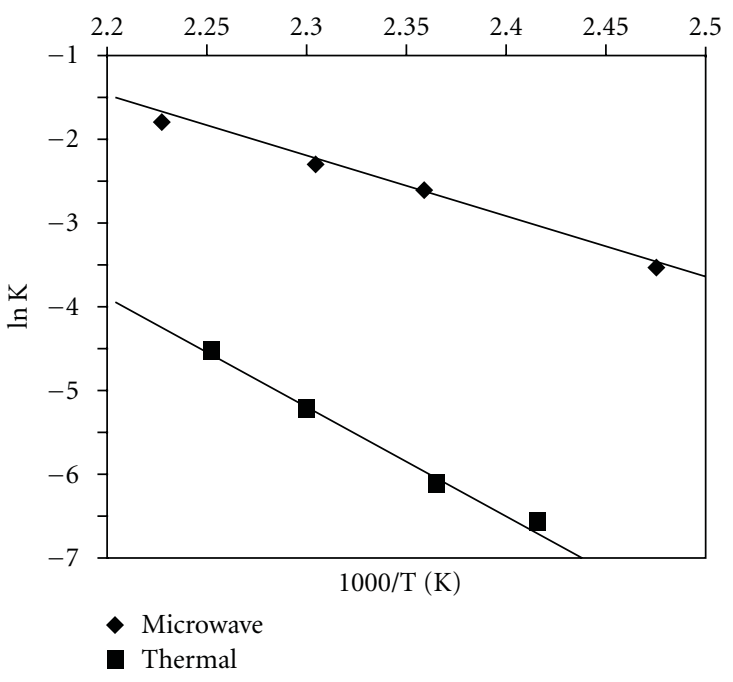

FIgURE 1: First-order kinetic plots for microwave (MW) and thermal $(\Delta)$ activation for the imidization reaction.

TABLE 1: Results from the Arrhenius plots in Figure 1.

\begin{tabular}{lcc}
\hline Heating mode & $\Delta H(\mathrm{~kJ} / \mathrm{mol})$ & $\log A$ \\
\hline MW & $57 \pm 5$ & $13 \pm 1$ \\
$\Delta$ & $105 \pm 14$ & $24 \pm 4$ \\
\hline
\end{tabular}

those obtained from conventional treatments. The activation energy $(\Delta H)$ determined from this treatment was $105 \mathrm{~kJ} / \mathrm{moL}$ for thermal imidization and $57 \mathrm{~kJ} / \mathrm{moL}$ for microwave imidization. The apparent activation energy is largely reduced. The same explanation, that is, a decrease in $\Delta G$, was also proposed for the decomposition reaction of sodium hydrogen carbonate in aqueous solution [40]. The physical phenomenon that provides the acceleration of the reaction rates is unclear. To support their results, the authors concluded that the microwave irradiation is not sufficiently energetic to cause either ionization or electronically excited state chemistry to occur, so the overall reaction stoichiometry is the same as that for the thermal reaction. The large difference observed in the kinetic parameters might be due to intermediate products being formed (which is discounted by the coincidence of the formation and disappearance rates for the products and reactants) or from the way in which the microwave radiation interacts with the reactants, the solvent, or the complexes between the solvent and reactants. And this would suggest that the acceleration is not due to the environment around the reactants, and therefore, must be due directly to the interaction of the microwave energy with the reactants, although the presence of solvent, and so forth, may have a secondary effect on the kinetic parameters [39].

This paper entails a critical review of microwave-assisted synthesis of CNTs supported with metal/oxide nanoparticles. Due to the extraordinary properties of CNTs, the resulting composites were closely investigated. Various applications of the CNT supported metal/oxide nanoparticle composites are also discussed.

\section{Synthesis of Metal and Metal Oxide Nanoparticles Supported on CNT by Conventional Methods}

The first demonstration of a metal nanoparticle-CNT hybrid, also known as metal nanoparticle decorated CNTs, was reported over a decade ago by Planeix et al. [41] via the hydrogen reduction of an organic ruthenium salt in the presence of SWCNTs. For example, when the light nanoparticles (NPs), such as $\mathrm{TiO}_{2}, \mathrm{ZnO}, \mathrm{CdS}$, and CdSe, were attached on CNTs with high conductivity, the photocatalytic properties increased dramatically [42-44]. Later, Kishi et al. [45] prepared a gas sensor for nitrogen dioxide $\left(\mathrm{NO}_{2}\right)$ using tungsten oxide $\left(\mathrm{WO}_{3}\right)$ nanoparticles fabricated on multiwalled CNTs (MWCNTs). The response of the gas sensor was found to be 4 times higher than that of MWCNTs-based gas sensor. In addition, the high surface areas of CNTs are ideal to maximize the efficiency of the catalyst [46-48]. Many approaches including assembling presynthesized NPs as building blocks on CNTs and spontaneous formation of NPs on CNTs have been applied to prepare NPs/CNTs [49-54].

Although the attachment of NPs on CNTs has been extensively studied, most of the methods involve a tedious process and usually require multistep reactions. Moreover, the amount of NPs loaded on CNTs is greatly limited, and this fact limits many practical applications [55]. For example, gold NPs were self-assembled onto the surface of solubilized CNTs through an interlinker of bifunctionalized molecule (17-1-pyrenyl)-13-oxo-heptadecanethiol (PHT) [56]. The MWCNTs were heated under reflux with concentrated nitric acid and were converted to acylchloride in $\mathrm{SOCl}_{2}$ and reacted for $96 \mathrm{~h}$. The interlinker PHT was mixed with the MWCNTs and sonicated for $30 \mathrm{~min}$ and stood for $8 \mathrm{~h}$. The precipitate was washed several times with ethanol under vacuum evaporator to remove the PHT and then the gold colloid was added. This was followed by stirring for $8 \mathrm{~h}$ at room temperature. The resulting solution was centrifuged and a dark brown solid was obtained. The transmission electron microscopy (TEM) image (refer to Figure 2) showed densely coated MWCNTs with gold nanoparticles with a narrow size distribution and an average size of $\sim 5 \mathrm{~nm}$.

The method took days to prepare one batch of CNT composites with proper dispersion of the NPs. It is reported that the pristine CNTs were heated under reflux using concentrated nitric acid before using them to remove the impurities and to introduce the carboxylic groups on the inherently inert CNTs, which in turn creates active sites to which the metal NP precursors can bind. The oxidation of CNTs in a concentrated acid has been actively reported, but the disadvantage is that long hours of treatment using high concentrated acid creates defects on the CNTs' sidewalls, which often results in damaging the CNTs, rendering them useless for their intended purpose. In this article [56], though it is reported that concentrated nitric acid was used, the reaction time for the oxidation process was not stated, which might have contributed to the long mixing of the CNTs and the NPs to get a strong attachment because the CNTs were severely damaged which results in the degradation of the composites. 


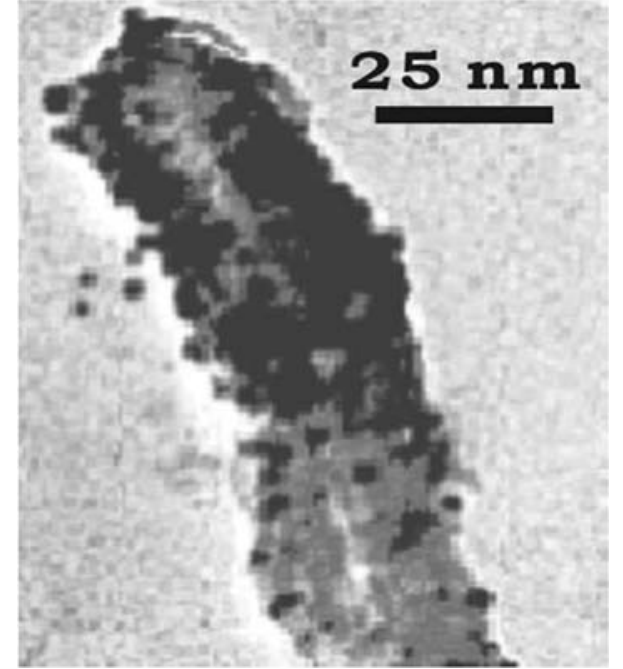

FIGURE 2: TEM image of gold nanoparticles self-assembled on the surface of s-MWCNTs through PHT [56].

This method is able to synthesize CNTs coated with gold NPs, but the TEM result shows lack of control on uniform dispersion of the NPs. It is also observed that not all the NPs are on the CNTs which means that there is no strong attachment of the NPs on the surface of the CNTs. A thick layer of NPs is observed on one side of the CNT whereas fewer particles on the other side. This observation shows that the NPs are on top of each other rather than being on the CNTs, which may result in fewer NPs in effect if the composites were to undergo heat treatment or alternatively be used for other applications.

Another multistep process was used by Smorodin et al. [57] to coat single-walled CNTs (SWCNTs) with gold NPs. In their study, SWCNTs were first sonicated in a mixture of $\mathrm{H}_{2} \mathrm{SO}_{4}: \mathrm{HNO}_{3}$ for $90 \mathrm{~min}$ to modify the walls of the CNTs. The nanotubes were then suspended in anhydrous dimethylformamide and refluxed in thionyl chloride for $24 \mathrm{~h}$. The precipitate was washed and rinsed to remove excess $\mathrm{SOCl}_{2}$, and this was followed by the immersion in ethylene diamine for five days. The nanotubes were rinsed again with THF and resuspended in $\mathrm{H}_{2} \mathrm{O}$ and reacted overnight with $N$-hydroxy succinimidyl biotin. After the final rinsing step, the biotin-terminated SWCNTs were suspended in $\mathrm{H}_{2} \mathrm{O}$ and a surfactant was added. Finally, gold colloids were added to the SWCNT suspension forming an extremely strong binding between the gold NPs and the SWCNTs. From the AFM image (refer to Figure 3), the authors concluded that a large fraction of SWCNTs has at least one NP attached, in most cases to one of the ends of the tube.

In this article [54] the authors reported the self-assembly method of preparing SWCNTs-coated gold NP composites. They reported a good dispersion of the NPs along the CNT with AFM results. Using this characterization equipment alone is not good enough to prove the success of the method in dispersion. It would have been better if they had used TEM images to confirm their results.

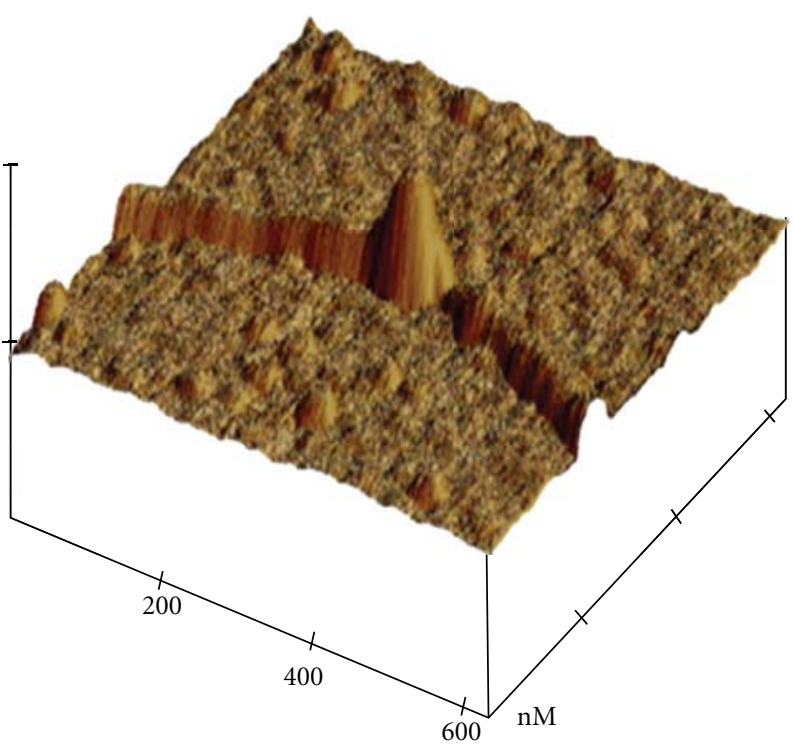

FIGURE 3: AFM image of a SWCNT-nanoparticle-SWCNT junction [57].

On the same grounds, another method of preparation of highly uniform and nicely dispersed gold NPs deposited on the CNTs was reported by Zhang et al. [58]. They reported reduced steps to synthesize the composites and also reduced the reaction time to less than $1 \mathrm{~h}$ using ultrasonic treatment. Figure 4 shows a high-magnification TEM image of a welldispersed and homogeneous coverage of the NPs on the nanotubes. This image demonstrates that the gold NPs are uniformly decorated on the walls of the CNTs with NP sizes of $8 \pm 3 \mathrm{~nm}$ and $20 \pm 2 \mathrm{~nm}$, which they report they were able to control.

The reported method appears to be a simpler and more efficient way of depositing the NPs of controllable sizes on the CNTs. The density of the NPs on the CNTs was controlled by changing the precursor salt, and the composites were prepared in less than an hour.

\section{Synthesis of Metal and Metal Oxide Nanoparticles Supported on CNT by Microwave Method}

Although the above methods were very successful and useful in coating CNTs outer surfaces with NPs, one important aspect is that simpler methods are desired in some cases, without the use of a long reaction time. In this instance, bulk production of composites will benefit from simple and faster methods, hence, the need for a microwave-assisted method for the synthesis of NPs on the CNTs. An impressive example was reported by Loupy et al. [59], who observed an increase in yield from $2 \%$ to $95 \%$ under microwave conditions, in the Leuckart reductive amination. These rate and yield enhancements have been suggested by some to be caused by specific, nonthermal microwave effects $[59,60]$.

Kim et al. [61] successfully dispersed ruthenium oxide NPs on MWCNTs using the microwave-polyol process. In 


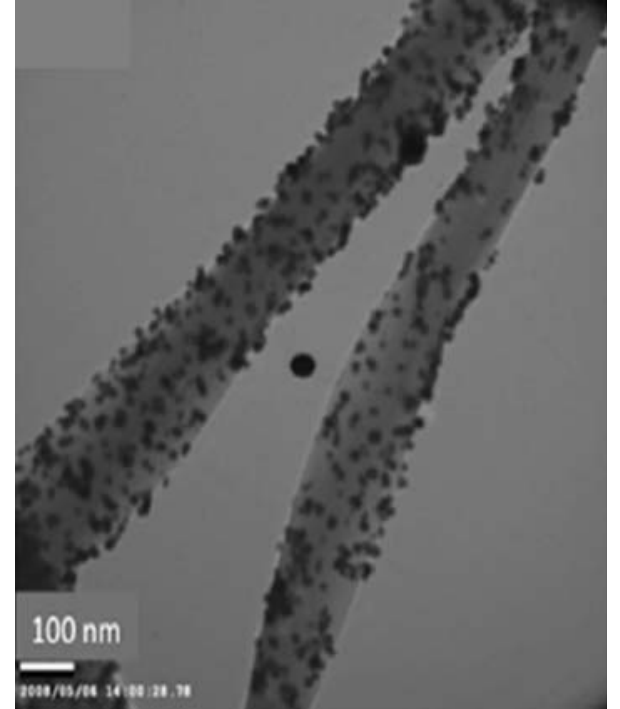

Figure 4: TEM image of synthesized MWCNT/Au nanocomposites with higher magnification (the black dot in the centre of the images is an imaging artifact) [58].

this process, the CNTs were initially treated with nitric acid to introduce functional groups on the surface of the CNTs and followed by sonication of the treated CNTs in diethylene glycol solvent. Ruthenium salt, $\mathrm{RuCl}_{3} \cdot n \mathrm{H}_{2} \mathrm{O}$, and sodium acetate $(\mathrm{NaAc})$ were dispersed in the CNTs and synthesized in a microwave digestion system. The reaction mixture was heated to $200^{\circ} \mathrm{C}$ for $2 \mathrm{~min}$ with microwave power of $1600 \mathrm{~W}$. They used HRTEM, Raman spectra, and TGA to characterize their materials, which indicated that CNTs were uniformly coated with crystalline and partially hydrous $\mathrm{RuO}_{2} \cdot 0.64 \mathrm{H}_{2} \mathrm{O}$ NPs of $2 \mathrm{~nm}$ diameter, and the loading amount of ruthenium oxide in the composite could be controlled up to $70 \mathrm{wt} . \%$.

Parts (a) and (b) of Figure 5 respectively show typical HRTEM images of the $70 \%$ and $20 \%$ ruthenium oxide/CNT nanocomposites showing remarkably uniform and high surface coverage. From these two TEM images, it is observed that the ruthenium oxide is selectively nucleated and uniformly deposited on the surface of the CNTs. Figure 5(b) gives evidence to the size and morphology control of the NPs when using the microwave method. The image (refer to Figure 5(b)) shows that the decrease of the precursor salt concentration still gives a uniform dispersion of the NPs, which means that the amount of the NPs on the CNTs can be controlled, which is not always possible when using a conventional method. Besides the good interaction between the CNTs and the microwaves, one possible explanation for the sidewall coating is that the CNTs were chemically pretreated with acid to functionalize them and remove the metal impurities formed during their manufacture and that introduces defects into the tube walls which act as active sites for binding with NPs. But in this instance, the oxidation process could have been done using the microwave in less time than in a conventional method that took $4 \mathrm{~h}$. CNTs have been found to display strong microwave absorption especially for functionalized CNTs; therefore using microwave could have saved more time. The overall results are good, and it is evident that the microwave method can synthesize composites of CNT supported NPs.

Chuncheng et al. [62] reported using the microwaveassisted method to coat the CNTs with zinc sulphide NPs. For the best anchoring of the ZnS NPs, the CNTs were first oxidized under reflux in concentrated nitric acid. In the first step, $\mathrm{Zn}(\mathrm{Ac})_{2} \cdot 2 \mathrm{H}_{2} \mathrm{O}$ and CNTs were added into a glycol solvent and ultrasonically treated to ensure uniform dispersion of the glycol solution. In the second step, $\mathrm{NaS} \cdot 9 \mathrm{H}_{2} \mathrm{O}$ was also dissolved in a glycol solution and then added to the CNT mixture. The new mixture was placed in a microwave oven and operated for $10 \mathrm{~min}$ with a power setting of $700 \mathrm{~W}$. The sample was characterized by TEM and XRD.

The TEM image (refer to Figure 6(a)) shows a welldispersed $\mathrm{ZnS}$ on the CNTs surface. From this image, it was concluded that the key factor in forming the well-dispersed composites was to ultrasonically treat the composition with a glycol solution. This was validated by the composites with no agglomerations as compared to the ones that were not treated ultrasonically with glycol solution and showed agglomerations. But looking at the TEM image (Figure 6(a)) some agglomerations exist in some parts of the composites but not as much as is reported on the image (image not shown here) where glycol was not used. It is evident that glycol reduces agglomerations; therefore, the agglomerations here may have been caused by the operating conditions of the microwave such as the high power, residence time, or temperature, though the temperature was not mentioned. The XRD pattern (refer to Figure 6(b)) further confirmed the presence of ZnS-coated MWCNTs composites with the mean size diameter calculated by the Debye-Scherrer equation to be $1 \mathrm{~nm}$. The diffraction peaks identified the sample as a mixture of sphalerite crystal ZnS and MWCNTs. The TEM image and XRD spectra confirmed the formation of NPs on the CNTs, and it can be concluded that the synthesis of the CNTs coated with NPs does not merely depend on the precursor salt, but also has a strong correlation with the synthesis conditions and the method used.

Ghosh et al. [63] reported the coating of platinum NPs on carbon-nitride nanotubes prepared by a microwaveassisted method compared to the $\mathrm{NaBH}_{4}$ chemical reduction method. In this study, $N$-doped MWCNTs were dispersed in 2-(2-methoxyethoxy)-ethanol solvent under mild sonication for the ease of $\mathrm{Pt}$ coating. $\mathrm{H}_{2} \mathrm{PtCl}_{6} \cdot \mathrm{H}_{2} \mathrm{O}$ was added to the above solution and stirred for $10 \mathrm{~min}$. The resultant solution was divided into six parts; one part underwent the $\mathrm{NaBH}_{4}$ route and the other five parts were subjected to microwave irradiation for 30, 50, 70, 90, and 110 s. Finally, the solid was washed and dried. These samples were labelled depending on the MW-irradiation times, for example, MW50, MW110, and so forth. According to the TEM characterization performed on the samples, the platinum NPs were nicely distributed on the CNTs in both methods as presented (parts (a), (b), and (c) of Figure 7). The Pt NPs grown by $\mathrm{NaBH}_{4}$ treatment (Figure 7(a)) were observed to be small (average diameter $3 \mathrm{~nm}$ ) and have a low density. However, those grown by microwave irradiation (refer to Figures 7 (b) and $7(\mathrm{c})$ ) were found to be larger and the population gradually 


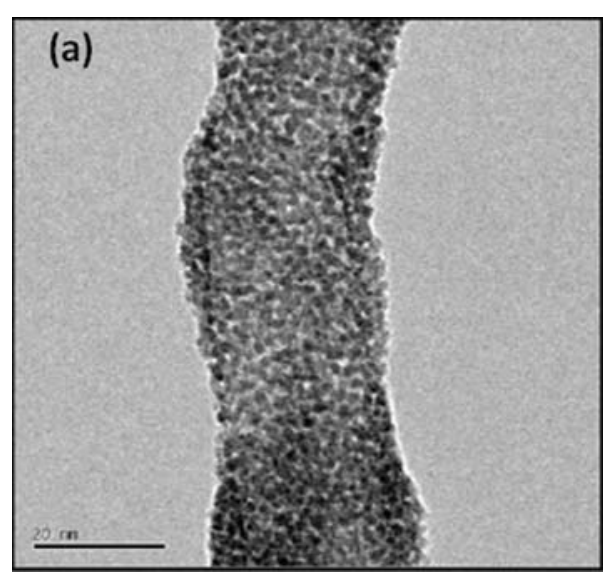

(a)

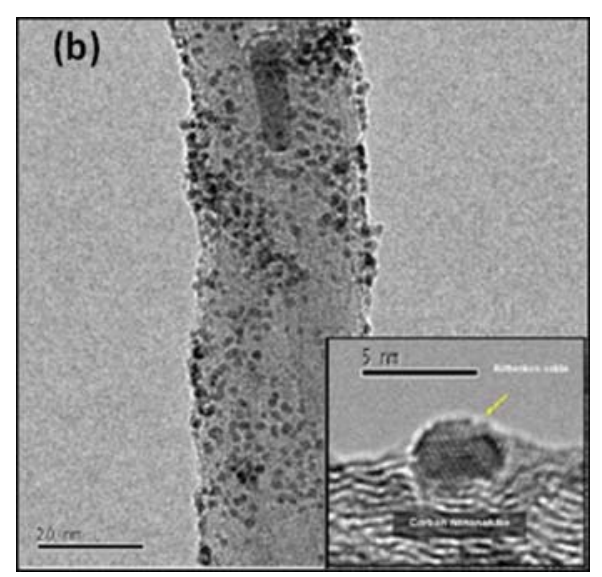

(b)

FIgURE 5: HRTEM images of ruthenium oxide/CNT nanocomposites of (a) $70 \mathrm{wt} . \%$ ruthenium oxide and (b) $20 \mathrm{wt} . \%$ ruthenium oxide [61].
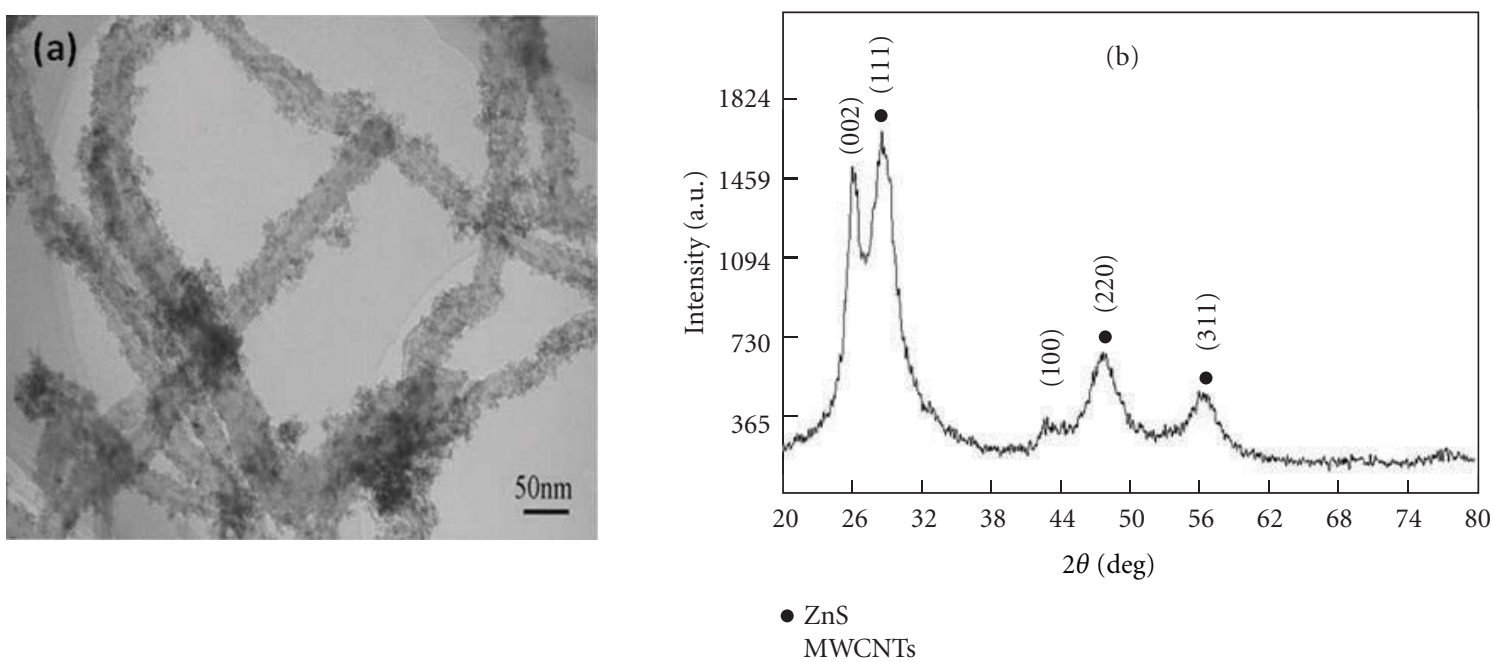

FIgURE 6: ZnS-nanoparticle-decorated MWCNTs, (a) TEM image and (b) XRD pattern [62].

increased with irradiation time. Microwave irradiation for 50 and $110 \mathrm{~s}$ resulted in 10.2 and $19.8 \mathrm{~nm}$ Pt particles, respectively. In this paper, the $\mathrm{NaBH}_{4}$-mediated chemical reduction process resulted in small size Pt NPs coated on the carbonnitride nanotubes with low density while the microwaveassisted method gave larger NPs with high population density. In the XPS spectrum (not shown here), the peak intensities showed that $\mathrm{NaBH}_{4}$ treatment led to the incomplete reduction of Pt ions; meanwhile, the microwave irradiation not only offered complete Pt reduction, but also enabled control of the particle size and density as a function of the irradiation time. The complete reduction of the Pt ions shows the uniform heating of the material to completion when using the microwave method and how comparative the method can be in synthesizing CNT composites in fewer steps. It is also useful that the authors have included the reaction mechanisms of both methods in the paper.

A comparative study was done in our earlier work [65] for the synthesis of $\mathrm{SnO}_{2} / \mathrm{CNTs}$ composites. A microwaveassisted method was used to synthesize MWCNT-coated
$\mathrm{SnO}_{2}$ and then compared to the conventional wet impregnation method. In both methods, the CNTs were first treated by oxidation to introduce the oxygen-containing functionalities to which the metal NP precursors can bind: $2 \mathrm{~h}$ for the conventional and $5 \mathrm{~min}$ for microwave method. On the second step, tin chloride was dissolved in distilled water and hydrochloric acid was added. The acid-treated CNTs were added to the above solution and magnetically stirred for an hour for the conventional method and heated under reflux for $5 \mathrm{~min}$ in the microwave reactor. It was found that $\mathrm{SnO}_{2}$ NPs were distributed on the CNT surface in both conventional wet impregnation and microwave-assisted method, and a better dispersion was found with the microwave method (refer to Figures 7(b) and 7(c)), which was also able to reduce the total reaction time of the synthesis from $4 \mathrm{~h}$ to $10 \mathrm{~min}$.

As shown in the TEM image (Figure 8(a)), the $\mathrm{SnO}_{2} \mathrm{NPs}$ were found to be distributed around and inside the CNTs. An average particle size of $3-5 \mathrm{~nm}$ was reported, which is in agreement with the XRD and SEM images. The XRD 

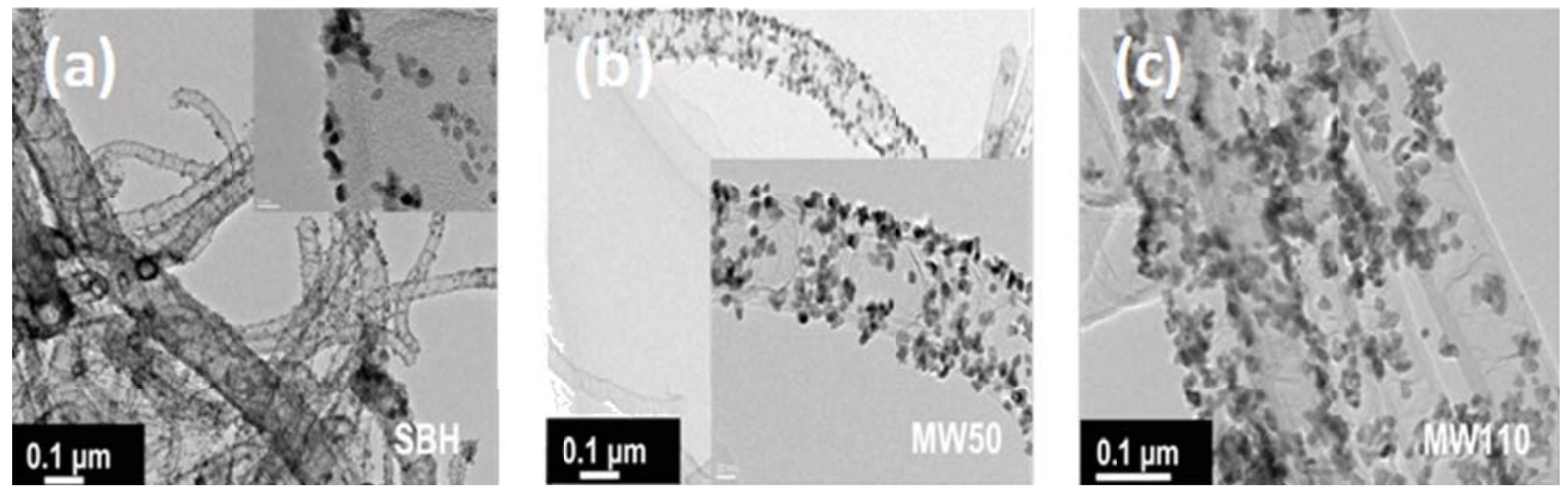

Figure 7: TEM images of Pt-CNx nanohybrids synthesized via (a) $\mathrm{NaBH}_{4}$-treated chemical reduction process, (b) microwave-assisted for $50 \mathrm{~s}$, and (c) microwave-assisted for $110 \mathrm{~s}[64]$.

spectra (Figure 8(b)) also confirmed the presence of the $\mathrm{SnO}_{2}$ in the composites prepared by both methods. A small variation in these conditions can lead to the production of $\mathrm{SnO}$ nanoparticles which were not desired in this case. The study illustrates the efficiency of the microwave method to form $\mathrm{SnO}_{2}$ NPs on CNT surface with good dispersion.

Using a microwave polyol method, Gan et al. [66] synthesized platinum $(\mathrm{Pt}) \mathrm{NPs}$ on CNTs. In this method, chloroplatinic acid $\left(\mathrm{H}_{2} \mathrm{PtCl}_{2}\right)$ and ethylene glycol (EG) were used as the platinum precursor and reducing agent, respectively. Sodium dodecyl sulphate (SDS) was added to the reaction system to prevent the colloids from aggregating into larger particles. The CNTs and SDS were dispersed into EG under ultrasonic treatment for $60 \mathrm{~min}$. Then $\mathrm{H}_{2} \mathrm{PtCl}_{2}$ solution was added into the solution under magnetic stirring. The resulting solution was treated at $150^{\circ} \mathrm{C}$ for $20 \mathrm{~min}$ in a focused single-mode microwave synthesis system. The products were centrifuged and washed with deionized water and absolute ethanol to remove any loose NPs and EG. Finally, the products were dried in vacuum at room temperature.

The authors reported a uniform coverage of the Pt NPs on CNTs that indicated that the functional groups were created throughout the surface of the CNTs (refer to Figure 9). The average NP size was calculated by the Debye-Scherrer formula and found to be $4.6 \mathrm{~nm}$. From these results it was proposed that the successful synthesis of Pt NPs with small size and good dispersion were attributed to the rapid microwave heating.

Some degree of agglomerations was observed along the surface of the CNT in the TEM image at low magnification (image not shown here). This result indicates that though the microwave method is efficient in reducing the reaction time, process optimization must be done for each composite system to improve the composite properties.

Wu et al. [67] reported the synthesis of CoNi/MWCNTs nanocomposites using microwave-assisted method. Acidtreated MWCNTs were mixed with $\mathrm{Co}(\mathrm{Ac})_{2} \cdot 4 \mathrm{H}_{2} \mathrm{O}$ and $\mathrm{Ni}(\mathrm{Ac})_{2} \cdot 4 \mathrm{H}_{2} \mathrm{O}$ in ethylene glycol and stirred for $24 \mathrm{~h}$ and then added $\mathrm{NaOH}$ to adjust the $\mathrm{pH}$. Several drops of hydrazine hydrate were added as a reducing agent, and the mixture was heated under microwave refluxing system for
$2 \mathrm{~min}$ and $600 \mathrm{~W}$. In this case, the sizes of the CoNi alloy NPs were controlled through adjusting atomic ratios of the metals to the CNTs. Experimental results have demonstrated that CoNi alloy NPs were attached on the MWCNTs with an average size of $15-48 \mathrm{~nm}$ which is consistent with the trend of the crystallite size calculated from the Debye-Scherrer formula. As can be observed from the images (refer to Figure 10), the number of CoNi alloy NPs attached on the CNTs increases with increasing the atomic ratios of metals to CNTs and this also goes for the particle size. The paper demonstrates clearly the controllable size and density population of the NPs when using the method. Changing the parameters of the synthesis allows uniform dispersion to heavily coated CNTs. Like many others $[61,62,68]$, the authors preferred to oxidize the CNTs under reflux and not use the advantage of microwave, but the nanocomposites were prepared in $2 \mathrm{~min}$, which dramatically reduced the total reaction time.

Pt NPs with different sizes supported on CNTs were prepared by microwave rapidly heating the EG solution of platinum salt with different $\mathrm{pH}$ [68]. For better anchoring the metal NPs, the CNTs were first oxidized by refluxing in concentrated $\mathrm{HNO}_{3}$ at $413 \mathrm{~K}$ for $4 \mathrm{~h}$. The preparation of $\mathrm{Pt} / \mathrm{CNTs}$ was carried out in EG solutions of $\mathrm{H}_{2} \mathrm{PtCl}_{6}$ precursor salts with different $\mathrm{pH}$ by microwave heating. The $\mathrm{pH}$ value was adjusted by dropping $0.8 \mathrm{moL} / \mathrm{L} \mathrm{KOH}$. The mixture was ultrasonically treated to ensure CNTs were uniformly dispersed in EG solution. The beaker was then placed in the centre of a household microwave oven (National, $2450 \mathrm{MHz}, 800 \mathrm{~W}$ ) and heated for $60 \mathrm{~s}$. The product was collected by filter and washed with absolute acetone and deionized water, then dried in a vacuum oven at $373 \mathrm{~K}$ for $12 \mathrm{~h}$. TEM examinations (refer to Figure 11) showed that Pt particles become smaller and more uniform when the synthesis $\mathrm{pH}$ increased from 3.4 to 9.2. It was found that $\mathrm{pH}$ was an important factor that influenced the particle size. Therefore, Pt particles size could be selected by adjusting the solution $\mathrm{pH}$ for preparing high-performance $\mathrm{Pt} / \mathrm{CNTs}$ catalyst for fuel cell application. Electrochemical measurements showed that the Pt/CNTs catalyst prepared from the synthesis 

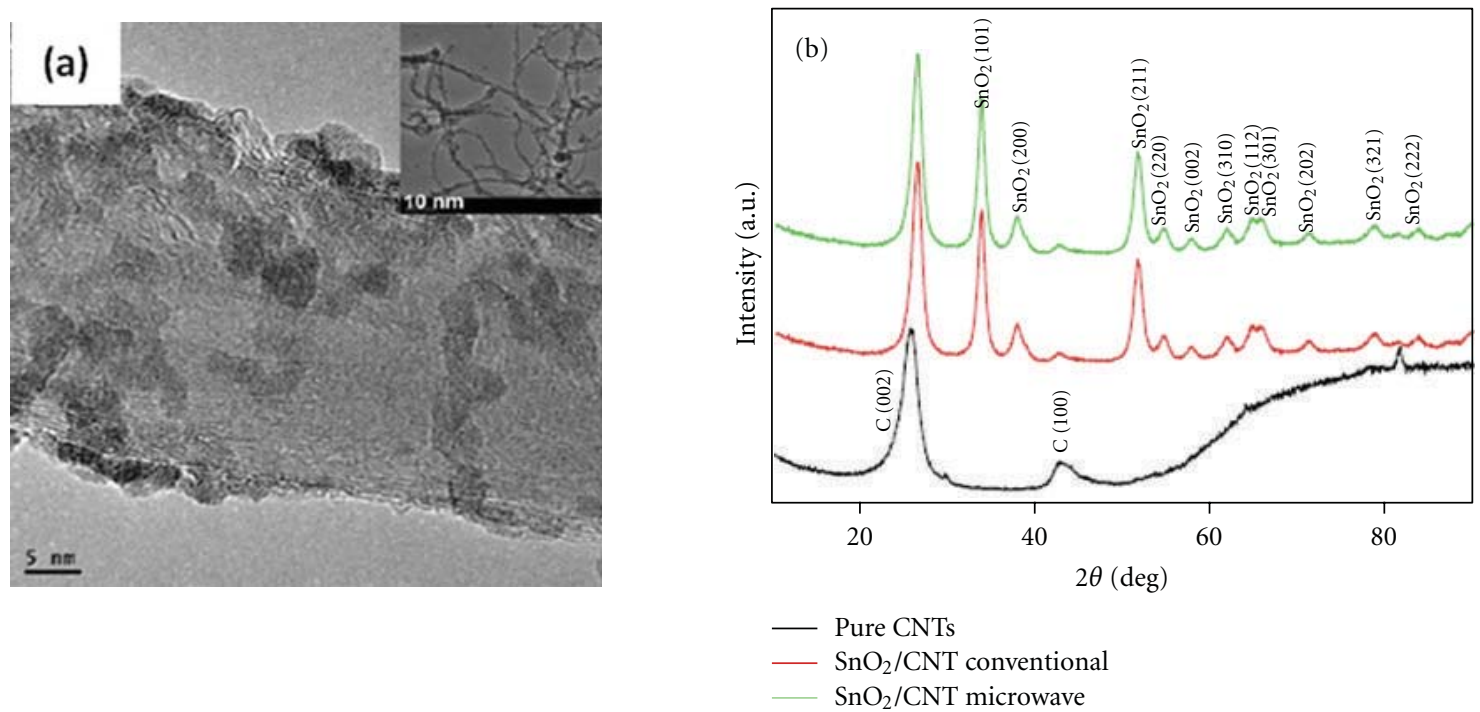

Figure 8: (a) HRTEM image of $\mathrm{SnO}_{2} / \mathrm{CNT}$ composite prepared by microwave (the inset shows a corresponding low-magnification image). (b) XRD patterns of pure CNTs and $\mathrm{SnO}_{2} / \mathrm{CNT}$ composite samples prepared by conventional and microwave wet impregnation methods [65].

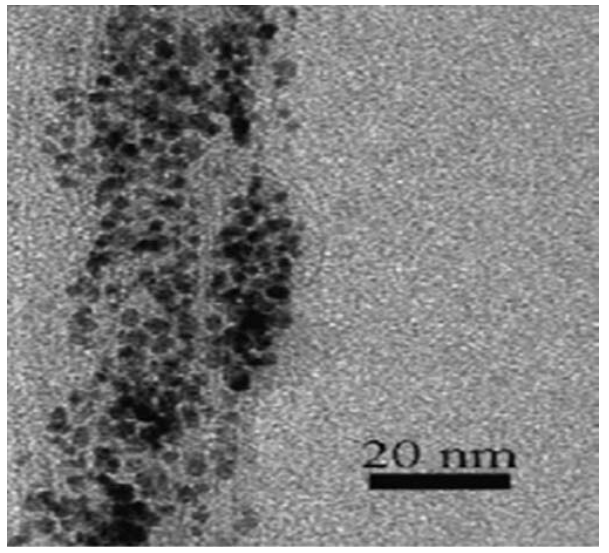

Figure 9: TEM images of Pt/CNTs heterostructures at higher magnification [66].

solution (pH 7.4) exhibited better performance for methanol electrooxidization than other samples.

The paper highlights the important role of $\mathrm{pH}$ of the reaction medium on the particle size along the CNTs. The authors suggest that, in addition to $\mathrm{pH}$ and good microwave absorption of reactants, other operating parameters are critical in improving the material properties.

Nanostructured $\mathrm{Mo}_{2} \mathrm{C} / \mathrm{CNTs}$ composites have been synthesized by using a methodology of microwave-assisted thermolytic molecular precursor with $\mathrm{Mo}(\mathrm{CO})_{6}$ as single source precursor. Typically, CNTs and molybdenum hexacarbonyl were put in an agate mortar and mixed for $15 \mathrm{~min}$. The completely homogeneous precursor mixture was put in a quartztube reactor with an inner diameter of about $10 \mathrm{~mm}$ and fluidized with a flow rate of $30 \mathrm{~mL} / \mathrm{min}$ argon for $2 \mathrm{~h}$ at room temperature to remove oxygen in the reactor and keep the reaction under the inert atmosphere. Next, the reactor was placed in a domestic microwave oven operating at $2.45 \mathrm{GHz}$ with a power of $800 \mathrm{~W}$. Finally, the resulting products were cooled to room temperature under argon. The microwave irradiation time varied from 1 to $15 \mathrm{~min}$ to investigate the formation mechanism. TEM images (Figure 12) show the well-distributed nanostructured $\mathrm{Mo}_{2} \mathrm{C}$ particles on the outer surface of CNTs and no agglomerations were observed. The mean size of $\mathrm{Mo}_{2} \mathrm{C}$ particles was reported to be about $5 \mathrm{~nm}$, which was in good agreement with the value from XRD. The reported results were compared with the results found by Liang et al. [69] who used the carbothermal hydrogen reduction method, in which the particle size of $\beta-\mathrm{Mo}_{2} \mathrm{C}$ also increased with increasing Mo loading. This shows and confirms the efficiency of the microwave-assisted method to get results comparable to other methods but in a faster and more economical way [70].

\section{Applications of Metal Oxides Nanoparticle-CNT Composites}

The possible applications of CNTs range from electronics, sensors, water purification, energy-storage devices, to functional fillers in composites. These have attracted both industrial and academic interest. Therefore, it is important that some of the basic knowledge is transferred to industry so that real and novel technologies appear commercially. Some of the applications are listed in the following (refer to Table 2 for summary).

4.1. Hydrogen Storage. In energy storage applications, materials with hydrogen storage capacity are very attractive. CNTs have been explored for many years for liquid and gas storage or gas filtration applications due to their cylindrical geometry and their nanoscale dimensions [71, 72]. Dillon et al. [73] were the first to propose that CNTs can be used 

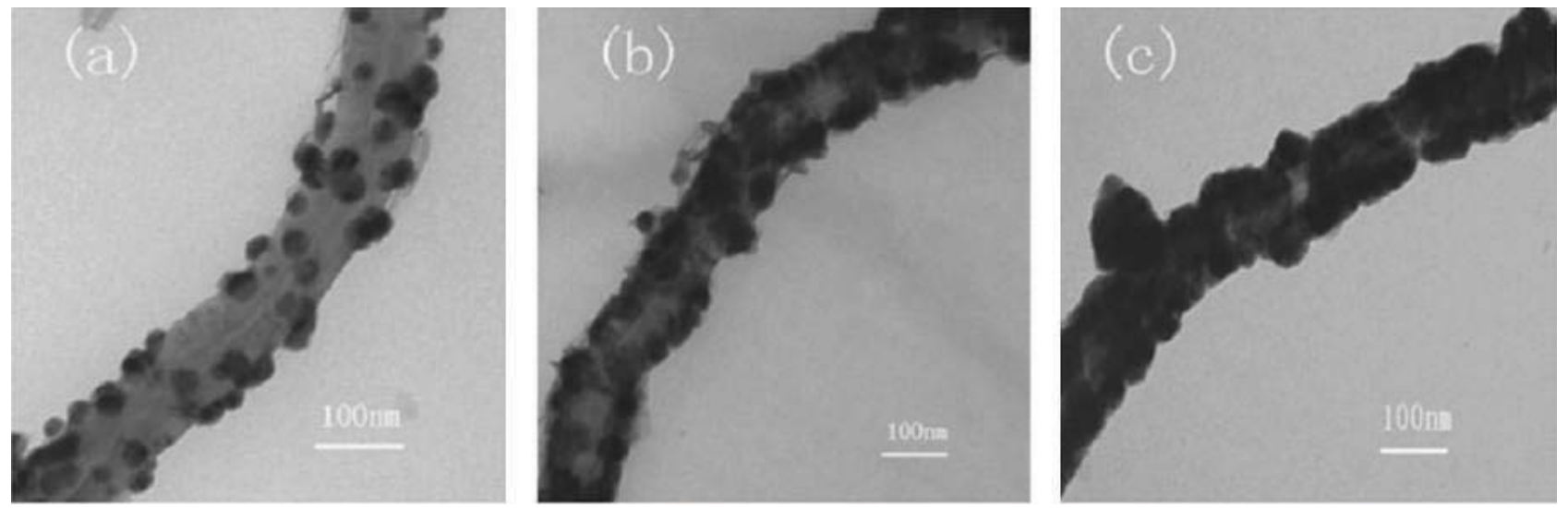

Figure 10: TEM images of CoNi/MWCNT nanocomposites obtained with the different atomic ratios (a) 7\%, (b) 12\%, and (c) 18\% [67].

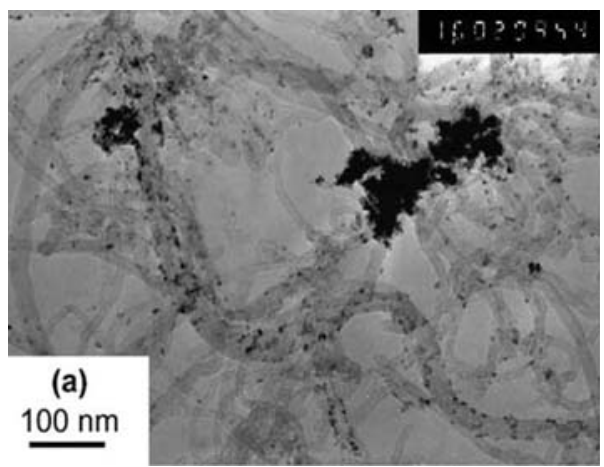

(a)

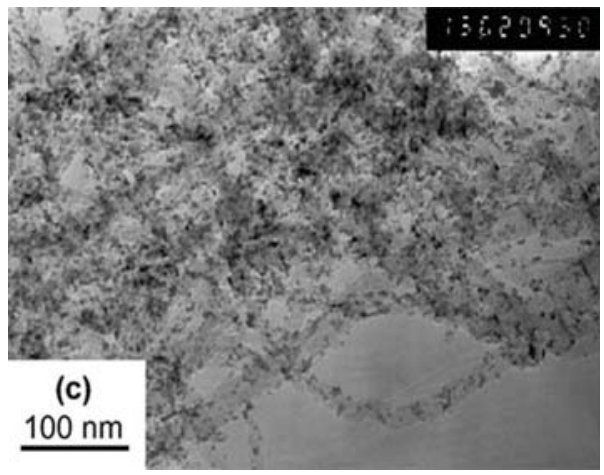

(c)

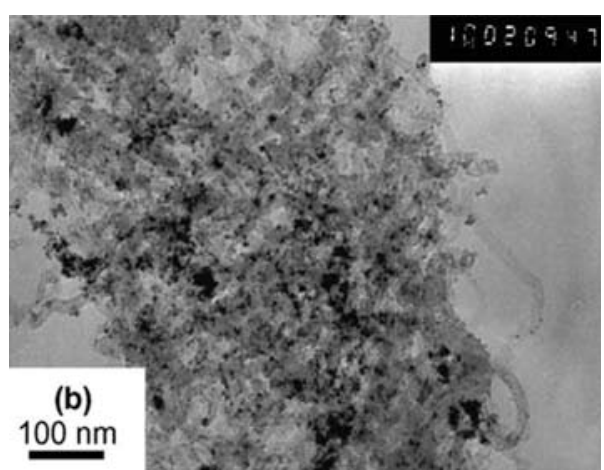

(b)

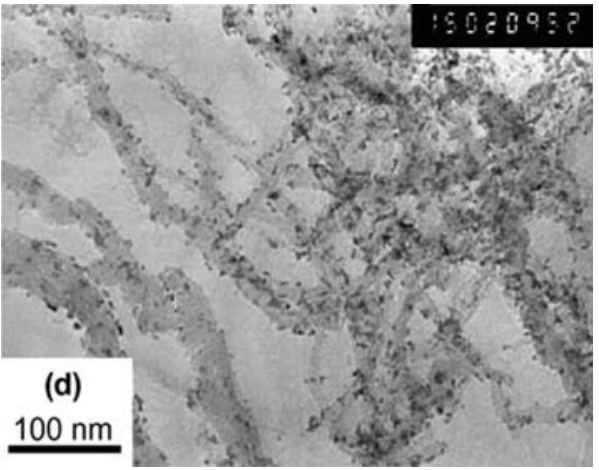

(d)

FIGURE 11: TEM images of microwave-synthesized Pt/CNTs from the ethylene glycol solutions of $\mathrm{H}_{2} \mathrm{PtCl}_{6}$ with different pH in the presence of CNTs: (a) pH: 3.6, (b) pH: 5.8, (c) pH: 7.4, and (d) pH: 9.2 [68].

as a hydrogen storage medium due to their lightweight and high hydrogen storage capacity. Because of the weak van der Waals interaction between CNTs and hydrogen molecules, the pure CNTs cannot store the required amount of hydrogen, but when functionalized with metal atoms, they are the most efficient hydrogen storage medium. Dillon et al. [73] studied the hydrogen adsorption properties of as-prepared soot containing 0.1-0.2 wt.\% SWCNTs and they estimated a hydrogen storage capacity of 5-10 wt.\% for pure SWCNTs. Park and Lee [74] showed that the hydrogen storage capacity of Pt/MWCNTs at $298 \mathrm{~K}$ and 100 bar is higher than that of MWCNTs. From the experimental results, it was found that $\mathrm{Pt}$ particles were homogeneously distributed on the MWCNTs surfaces. The amount of hydrogen storage capacity increased in proportion to the $\mathrm{Pt}$ content, with $\mathrm{Pt}$ 5/MWCNTs (3.72wt.\%) exhibiting the largest hydrogen storage capacity. The superior amount of hydrogen storage was linked to an increase in the number of active sites and the optimum-controlled micropore volume for hydrogen adsorption due to the well-dispersed Pt particles. Therefore, it can be concluded that Pt particles play an important role in hydrogen storage characteristics due to the hydrogen 


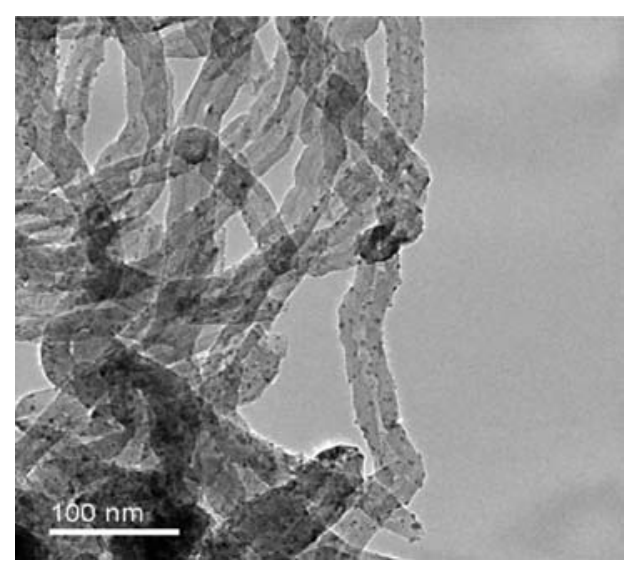

(a)

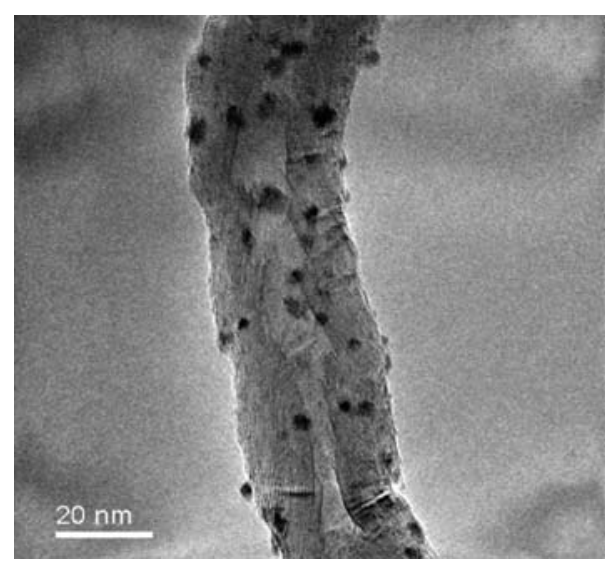

(b)

FIGURE 12: TEM images of the $\mathrm{Mo}_{2} \mathrm{C} / \mathrm{CNTS}$ with the $16.7 \mathrm{wt} \%$ Mo calculated loading at two different magnifications [70].

spillover effect [74]. Yang et al. [75] reported the electrochemical hydrogen storage properties of Ni NP-coated SWCNT electrodes. The characteristic properties of the SWCNT samples coated with 4-12 wt.\% Ni NPs were examined. According to the electrochemical test results, the highest electrochemical discharge capacity of $1404 \mathrm{mAh} / \mathrm{g}$ was obtained for the SWCNT electrode coated with $8 \mathrm{wt} . \%$ Ni NPs, which corresponded to $5.27 \mathrm{wt} . \%$ hydrogen storage. This enhancement of electrochemical hydrogen storage capacity was ascribed to the fact that the Ni NPs act as a redox site, thus leading to an improved electrochemical hydrogen storage capacity. The results indicated that the SWCNTs coated with Ni NPs are a potential material for hydrogen storage [75].

4.2. Energy Storage and Related Applications. Xu et al. [76] prepared MWCNTs filled and coated with $\mathrm{SnO}_{2}$ NPs using a simple one-step chemical solution method at $50^{\circ} \mathrm{C}$. The $\mathrm{SnO}_{2} / \mathrm{MWCNTs}$ hybrids were characterized by TEM and XRD. XRD patterns and HRTEM images validated that the $\mathrm{SnO}_{2} \mathrm{NPs}$ had an average size of $3-5 \mathrm{~nm}$. The homogenously distributed NPs on MWCNTs exhibited enhanced discharge capacity and cycling performance because MWCNTs prevented the volume expansion and increased the electric conductivity. The sample showed initial discharge capacities of 2127.4 and $1880.2 \mathrm{mAh} / \mathrm{g}$ at 70 and $200 \mathrm{mAh} / \mathrm{g}$ and remained at 469 and $362 \mathrm{mAh} / \mathrm{g}$ after 40 cycles with a loss of 1.2 and $1.5 \%$ per cycle under these current densities. Though the capacity retained only $20 \%$ of the first cycle, it was still larger than the theoretical capacity of graphite $(372 \mathrm{mAh} / \mathrm{g})$. Therefore, the results demonstrated that they had a better cycling performance at large discharge/charge current densities [76].

Another $\mathrm{SnO}_{2}$ coated on CNTs study was reported by Wang et al. [77] who used a novel thioglycolic acid assisted one-step wet chemical method. The coatings were characterized by XRD and TEM. The composites showed a good lithium intercalation/deintercalation performance when used as anode materials for lithium-ion batteries. Their high charge capacities and durability against decay are ascribed to the good dispersion of $\mathrm{SnO}_{2}$ on MWCNTs and small particle size, which is a benefit of using $\mathrm{SnO}_{2}$, and to the release of the stress caused by the drastic volume variation during the lithium intercalation/deintercalation process [77]. Zhao et al. [78] investigated Pt-Sn NPs on MWCNTs and explored their use as an anode catalyst for a direct ethanol fuel cell, which may find use as a potential mobile power source. They compared the functionalization of the CNTs with that of carbon black and observed a better performance in the former, which they attributed to the structural difference of CNTs over carbon black, higher electric properties, and lower organic impurities of CNTs as compared to their carbon black sample [78]. Matsumoto et al. [82] reported that $12 \mathrm{wt} . \%$ Pt deposited onto CNTs results in 10\% higher voltages than 29 wt.\% Pt deposited on carbon black; this ultimately reduces the $\mathrm{Pt}$ wastage by $60 \%$ in polymer-electrolyte fuel cells. The higher performance of the Pt-decorated CNTs was attributed to (i) well-dispersed platinum NPs on the CNTs allowing more triple-phase boundaries, (ii) high electric conductivity, and (iii) networks and interiors of the CNTs, which might consist of spaces for gas diffusion. Sakthivel et al. [83] reported the deposition of platinum electrocatalysts on MWCNTs with high loading prepared using a microwaveassisted polyol reduction method and employed for direct methanol fuel cells (DMFCs). Single cell DMFC measurements were performed in a membrane-electrode assembly (MEA) with $5 \mathrm{~cm}^{2}$ active area and very low catalyst loading $\left(0.25 \mathrm{mg} \cdot \mathrm{cm}^{-2}\right.$ of noble metal on both anode and cathode). The DMFC performance of the surfactant stabilized cathode catalyst obtained by the new method described here revealed that the power density was three times higher than for a commercial catalyst used for comparison and two times higher than for an unstabilized CNT-supported catalyst. Much higher power densities were observed for the two samples with CNT as support compared with the Vulcan carbonsupported catalyst. The maximum power density of the DMFC with the surfactant stabilized Pt/CNT catalyst was $74 \mathrm{mWcm}^{-2}$, while only $30 \mathrm{mWcm}^{-2}$ could be achieved with the commercial catalyst [83]. Kim et al. [61] investigated the dispersion of ruthenium oxide NPs on MWCNTs 
TABLE 2: Summary of CNT-supported metal/oxide applications.

\begin{tabular}{lccl}
\hline CNT type & Metal/oxide & Application & Ref. \\
\hline MWCNTs & $\mathrm{RuO}_{2}$ & Electrochemical capacitors & Kim et al. [61] \\
MWCNTs & $\mathrm{Pt}$ & Hydrogen storage & Park et al. [74] \\
SWCNTs & $\mathrm{Ni}$ & Electrochemical hydrogen storage & Yang et al. [75] \\
MWCNTs & $\mathrm{SnO}_{2}$ & Lithium-ion batteries & Xu et al. [76] \\
MWCNTs & $\mathrm{SnO}_{2}$ & & Wang et al. [77] \\
MWCNTs & $\mathrm{Pt}-\mathrm{Sn}$ & Catalyst & Zhao et al. [78] \\
MWCNTs & $\mathrm{Co}$ & & Zhang et al. [79] \\
MWCNTs & $\mathrm{Pd}$ & Fuel Cells & Ye et al. [79-81] \\
MWCNTs & $\mathrm{Pt}$ & & Matsumoto et al. [82] and Sakthivel et al. [83] \\
MWCNTs & $\mathrm{SnO}_{2}$ & Espinosa et al. [84] and Liu et al. [85] \\
MWCNTs & $\mathrm{WO}_{3}$ & Gas sensor & Wongchoosuk et al. [86] \\
SWCNTs & $\mathrm{Pd}$ & & Lu et al. [87] \\
MWCNTs & $\mathrm{Pt}$ & Shi et al. [88] and Qiaocui et al. [89] \\
SWCNTs & $\mathrm{TiO}_{2}$ & Photocatalytic & Dechakiatkrai et al. [90] \\
DWCNTs & $\mathrm{Ru}$ & Field emission & Liu et al. [91]
\end{tabular}

synthesized via microwave-polyol process combined with forced hydrolysis without additional thermal oxidation or electrochemical oxidation treatment. Characterization of the samples confirmed the uniform coating with crystalline and partially hydrous $\mathrm{RuO}_{2} \cdot 0.64 \mathrm{H}_{2} \mathrm{O}$ NPs of $2 \mathrm{~nm}$ diameter and the loading amount of ruthenium oxide in the composite could be controlled up to $70 \mathrm{wt} . \%$. The specific capacitance was $450 \mathrm{Fg}^{-1}$ of ruthenium oxide/CNT composite electrode with $70 \mathrm{wt} . \%$ ruthenium oxide at the potential scan rate of $10 \mathrm{mVs}^{-1}$, and it decreased to $362 \mathrm{Fg}^{-1}$ by $18 \%$ at $500 \mathrm{mVs}^{-1}$. The specific capacitance of ruthenium oxide in the composite was $620 \mathrm{Fg}^{-1}$ of ruthenium oxide at $10 \mathrm{mVs}^{-1}$. The ruthenium oxide NPs in ruthenium oxide/CNT nanocomposite electrodes had a high ratio of outer charge to total charge of 0.81 , which confirmed the high-rate capability of the composite through the preparation of the nanosized ruthenium oxide particles on the external surface of CNTs [61]. Liu et al. [91] studied the field emission properties of doublewalled CNTs (DWCNTs), which are remarkably improved by decorating their surface with ruthenium metal NPs. The Ru NPs were attached effectively on the surface of DWCNTs via a chemical procedure. The Ru-decorated DWCNTs showed lower turn-on voltage, higher emission current density, and improved emission uniformity compared with pristine DWCNTs. The effect of Ru NPs, on the work function and density of states, was evaluated by the first-principles calculation. The enhanced field emission properties of $\mathrm{Ru}-$ DWCNTs were mainly attributed to the Ru NPs which increased the field enhancement factor and the density of emission sites. Their results indicated that the Ru-decorated DWCNTs can be used as an effective field emitter for various field emission devices [91].

4.3. Catalysis. Selective hydrogenation catalysts are crucial in the petrochemical and fine chemical industries for the synthesis of a wide variety of chemicals [80]. Zhang et al. [79] found that CNTs coated with Co NPs were catalytic for the formulation of 1-octene with a high activity and excellent region selectivity. Ye et al. [81, 92, 93] also demonstrated in their work on the deposition of Pd NPs on MWCNTs in supercritical $\mathrm{CO}_{2}$ that the Pd-MWCNTs composites were excellent catalysts for the hydrogenation of olefins, including the conversion of stilbene into 1,2-diphenylethane, with conversions of $96 \%$ after 10 min exposure. Other metal NPs used for catalysis include $\mathrm{Ru}-\mathrm{Sn}$ and $\mathrm{Ru}-\mathrm{Pt}$ alloys for heterogeneous catalysis [94], Au [95], Pt-catalyzed hydrogen peroxide oxidation [96], gold-thiol monocapped NPs [10], and Pd, Pt, $\mathrm{Au}$, and $\mathrm{Ag}$ for environmental catalysis [23]. Dechakiatkrai et al. [90] prepared and characterized $\mathrm{TiO}_{2} / \mathrm{SWCNT}$ composites for photocatalytic applications. The photocatalytic activity of $\mathrm{TiO}_{2}$ and the $\mathrm{TiO}_{2} /$ SWCNT composite was investigated using the photooxidation of methanol in sulphuric acid as supporting electrolyte. The results indicated that the $\mathrm{TiO}_{2} / \mathrm{SWCNTs}$ composite enhances the photocatalytic activity compared to $\mathrm{TiO}_{2}$ alone. Electrochemical studies of the $\mathrm{TiO}_{2} / \mathrm{SWCNT}$ composite were also carried out in various supporting electrolytes, and the presence of SWCNTs in the $\mathrm{TiO}_{2}$ film was found to be able to photocatalyze the oxidation of methanol, 10 times higher than a pure $\mathrm{TiO}_{2}$ electrode. This is an attractive way for further application in the field of photocatalytic decomposition of organic compounds in aqueous media under UV irradiation and a potential material for applications involving photocatalyzed fuel cells [90].

4.4. Sensors. CNTs have been effective as sensing elements utilizing their electrical, electrochemical, and optical properties. Detecting a low concentration of toxic gas is important for environmental purposes and chemical safety. CNTs have been highlighted as promising gas-sensing elements due to the 1-dimensional electronic structure with all the atoms residing only on the surface. CNTs have advantages over conventional metal-oxide-based sensors in terms of power consumption, sensitivity, miniaturization, and reliable mass production [97]. Espinosa et al. [84] have shown that the addition of a small quantity of $\mathrm{O}_{2}$-functionalized MWCNTs to metal oxides can significantly improve the detection 
capability of metal oxide-based sensors at low operating temperatures. In particular, microsensors based on $\mathrm{SnO}_{2} /$ MWCNTs hybrid films operated at room temperature showed the higher sensitivity towards $\mathrm{NO}_{2}$ in the ppb range among the different materials studied. Additionally, the sensors showed a total recovery of their baseline resistance and reasonable response and recovery times. The results suggested that there is an optimum amount of CNTs to be added to each particular metal oxide in order to enhance responsiveness [84].

Liu et al. [85] reported the gas sensing properties of MWCNTs coated with $\mathrm{SnO}_{2}$. It was found that the sensor exhibited good sensing responses to liquefied petroleum gas (LPG) and ethanol gas $\left(\mathrm{C}_{2} \mathrm{H}_{5} \mathrm{OH}\right)$. Furthermore, the gas sensor responses increased linearly with the increment of the gas concentrations of LPG and ethanol and the sensor exhibits a fast response and a good recovery. The fabrication of hydrogen gas sensors based on undoped and 1 wt.\% MWCNT-doped tungsten oxide $\left(\mathrm{WO}_{3}\right)$ thin films by means of the powder mixing and electron beam (E-beam) evaporation technique were reported by Kerdcharoen et al. [97]. Hydrogen sensing properties of the thin films have been investigated at different operating temperatures and gas concentrations ranging from $100 \mathrm{ppm}$ to $50,000 \mathrm{ppm}$. The results indicated that the MWCNT-doped $\mathrm{WO}_{3}$ thin film exhibits high sensitivity and selectivity to hydrogen. Thus, MWCNT doping based on E-beam coevaporation was shown to be an effective means of preparing hydrogen gas sensors with enhanced sensing and reduced operating temperatures. At any operating temperature, the sensor response of the MWCNT-doped $\mathrm{WO}_{3}$ thin film is higher than that of the undoped $\mathrm{WO}_{3}$ thin film. Specifically, at the optimum operating temperature $\left(350^{\circ} \mathrm{C}\right)$, MWCNT-doped $\mathrm{WO}_{3}$ thin film yields a $26.9 \%$ higher response than the undoped one. This should prove to be useful for developing high-performance $\mathrm{H}_{2}$ gas sensors [86]. Lu et al. [87] have immobilized palladium NPs on SWCNTs and applied this in the detection of methane. The methodology showed advantages over conventional catalytic beads and metal oxide sensors with a tenfold increase in sensitivity and reduced power consumption by a factor of 100. Both Shi et al. [88] and Qiaocui et al. [89] used CNT-supported Pt NPs to fabricate a cholesterol biosensor involving the immobilization of the Pt-modified CNTs and the cholesterase enzyme in a solgel matrix on an electrode. The detection of cholesterol occurred indirectly using the hydrogen peroxide produced by the action of the enzyme and allowed the sensor to have a low detection limit $(1.4 \mathrm{~mm})$ over a good linear range (4$100 \mathrm{~mm}$ ). The Pt-CNTs also limited the effect of interferents compared to bulk materials or CNTs alone [88]. Also of note is the Pt-CNT-supported catalysis of both hydrogen peroxide and cysteine for the bioanalytical sensing of both species [90].

\section{Conclusions}

In this paper, the challenges of the preparation of metal and metal-oxide-nanoparticle-coated CNTs have been addressed using the microwave-assisted method. The quality and rapid formation of uniform small-sized nanomaterials under microwave conditions have demonstrated to be an effective and alternative way of synthesizing nanoparticle-coated CNTs. As summarized here, the method has shown that it can be used for any metal oxide and CNTs, and by varying the deposition material and deposition time, one can control the size and distribution of metal nanoparticles on CNTs surfaces. The published results have shown that microwave synthesis is a user-friendly method rarely damaging the materials. As the method is being used for various reasons (end-product), different routes and strategies should be applied depending on the final product to be achieved. The existence of a specific microwave effect is still a debate.

\section{Acknowledgment}

S. C. Motshekga, S. K. Pillai, and S. S. Ray would like to thank CSIR and DST for the financial support.

\section{References}

[1] S. Iijima, "Helical microtubules of graphitic carbon," Nature, vol. 354, no. 6348, pp. 56-58, 1991.

[2] P. Kim, L. Shi, A. Majumdar, and P. L. McEuen, "Thermal transport measurements of individual multiwalled nanotubes," Physical Review Letters, vol. 87, no. 21, Article ID 215502, pp. 2155021-2155024, 2001.

[3] S. Berber, Y. K. Kwon, and D. Tománek, "Unusually high thermal conductivity of carbon nanotubes," Physical Review Letters, vol. 84, no. 20, pp. 4613-4616, 2000.

[4] E. W. Wong, P. E. Sheehan, and C. M. Lieber, "Nanobeam mechanics: elasticity, strength, and toughness of nanorods and nanotubes," Science, vol. 277, no. 5334, pp. 1971-1975, 1997.

[5] C. T. White and T. N. Todorov, "Carbon nanotubes as long ballistic conductors," Nature, vol. 393, no. 6682, pp. 240-241, 1998.

[6] A. Javey, J. Guo, Q. Wang, M. Lundstrom, and H. Dai, "Ballistic carbon nanotube field-effect transistors," Nature, vol. 424, no. 6949, pp. 654-657, 2003.

[7] T. Dürkop, S. A. Getty, E. Cobas, and M. S. Fuhrer, "Extraordinary mobility in semiconducting carbon nanotubes," Nano Letters, vol. 4, no. 1, pp. 35-39, 2004.

[8] Z. Yao, C. L. Kane, and C. Dekker, "High-field electrical transport in single-wall carbon nanotubes," Physical Review Letters, vol. 84, no. 13, pp. 2941-2944, 2000.

[9] Y. Zhang, Q. Zhang, Y. B. Li, N. Wang, and J. Zhu, "Coating of carbon nanotubes with tungsten by physical vapor deposition," Solid State Communications, vol. 115, no. 1, pp. 51-55, 2000.

[10] L. Han, W. Wu, F. L. Kirk et al., "A direct route toward assembly of nanoparticle-carbon nanotube composite materials," Langmuir, vol. 20, no. 14, pp. 6019-6025, 2004.

[11] W. X. Chen, J. Y. Lee, and Z. Liu, "Preparation of Pt and PtRu nanoparticles supported on carbon nanotubes by microwaveassisted heating polyol process," Materials Letters, vol. 58, no. 25, pp. 3166-3169, 2004.

[12] A. Kolmakov and M. Moskovits, "Chemical sensing and catalysis by one-dimensional metal-oxide nanostructures," Annual Review of Materials Research, vol. 34, pp. 151-180, 2004.

[13] J. Zhao, "Gas adsorption of carbon nanotubes: tube-molecule interaction and technological applications," Current Nanoscience, vol. 1, no. 2, pp. 169-176, 2005. 
[14] N. Sinha, J. Ma, and J. T. W. Yeow, "Carbon nanotube-based sensors," Journal of Nanoscience and Nanotechnology, vol. 6, no. 3, pp. 573-590, 2006.

[15] P. M. Ajayan and O. Z Zhou, "Applications of carbon nanotubes," in Carbon Nanotubes: Synthesis, Structure, Properties, and Applications, M. S. Dresselhaus, G. Dresselhaus, and P. Avouris, Eds., vol. 80 of Topics in Applied Physics, pp. 391-425, 2001.

[16] W. B. Choi, D. S. Chung, J. H. Kang et al., "Fully sealed, highbrightness carbon-nanotube field-emission display," Applied Physics Letters, vol. 75, no. 20, pp. 3129-3131, 1999.

[17] P. L. McEuen, "Single-wall carbon nanotubes," Physics World, vol. 13, no. 6, pp. 31-36, 2000.

[18] P. Kim and C. M. Lieber, "Nanotube nanotweezers," Science, vol. 286, no. 5447, pp. 2148-2150, 1999.

[19] P. Simon and Y. Gogotsi, "Materials for electrochemical capacitors," Nature Materials, vol. 7, no. 11, pp. 845-854, 2008.

[20] M. S. Dresselhaus, K. A. Williams, and P. C. Eklund, "Hydrogen absorption in carbon materials," Materials Research Society Bulletin, vol. 24, no. 11, pp. 45-50, 1999.

[21] A. C. Dillon, K. M. Jones, T. A. Bekkedahl, C. H. Kiang, D. S. Bethune, and M. J. Heben, "Storage of hydrogen in singlewalled carbon nanotubes," Nature, vol. 386 , no. 6623, pp. 377379, 1997.

[22] R. V. Hull, L. Li, Y. Xing, and C. C. Chusuei, "Pt nanoparticle binding on functionalized multiwalled carbon nanotubes," Chemistry of Materials, vol. 18, no. 7, pp. 1780-1788, 2006.

[23] B. Xue, P. Chen, Q. Hong, J. Lin, and K. L. Tan, "Growth of Pd, Pt, Ag and Au nanoparticles on carbon nanotubes," Journal of Materials Chemistry, vol. 11, no. 9, pp. 2378-2381, 2001.

[24] K. R. Reddy, K. P. Lee, A. I. Gopalan, M. S. Kim, A. M. Showkat, and Y. C. Nho, "Synthesis of metal (Fe or Pd)/Alloy (Fe-Pd)-nanoparticles-embedded multiwall carbon nanotube/sulfonated polyaniline composites by $\gamma$ irradiation," Journal of Polymer Science, A, vol. 44, no. 10, pp. 3355-3364, 2006.

[25] C. Mao, D. J. Solis, B. D. Reiss et al., "Virus-based toolkit for the directed synthesis of magnetic and semiconducting nanowires," Science, vol. 303, no. 5655, pp. 213-217, 2004.

[26] W. Q. Han and A. Zettl, "Coating single-walled carbon nanotubes with tin oxide," Nano Letters, vol. 3, no. 5, pp. 681-683, 2003.

[27] Y. Wang, Z. Iqbal, and S. Mitra, "Microwave-induced rapid chemical functionalization of single-walled carbon nanotubes," Carbon, vol. 43, no. 5, pp. 1015-1020, 2005.

[28] Q. C. Xu, J. D. Lin, J. Li, X. Z. Fu, Y. Liang, and D. W. Liao, "Microwave-assisted synthesis of MgO-CNTs supported ruthenium catalysts for ammonia synthesis," Catalysis Communications, vol. 8, no. 12, pp. 1881-1885, 2007.

[29] M. Nüchter, B. Ondruschka, W. Bonrath, and A. Gum, "Microwave assisted synthesis-a critical technology overview," Green Chemistry, vol. 6, no. 3, pp. 128-141, 2004.

[30] D. V. Stass, J. R. Woodward, C. R. Timmel, P. J. Hore, and K. A. McLauchlan, "Radiofrequency magnetic field effects on chemical reaction yields," Chemical Physics Letters, vol. 329, no. 1-2, pp. 15-22, 2000.

[31] P. Lidström, J. Tierney, B. Wathey, and J. Westman, "Microwave assisted organic synthesis- a review," Tetrahedron, vol. 57, no. 51, pp. 9225-9283, 2001.

[32] G. Whittaker, "Microwave chemistry," School of Science Review, vol. 85, no. 312, pp. 87-94, 2004.

[33] S. Das, A. K. Mukhopadhyay, S. Datta, and D. Basu, "Prospects of microwave processing: an overview," Bulletin of Materials Science, vol. 32, no. 1, pp. 1-13, 2009.
[34] L. Vovchenko, L. Matzui, M. Zakharenko, M. Babich, and A. Brusilovetz, "Thermoexfoliated graphite as support for production of metal-graphite nanocomposites," Journal of Physics and Chemistry of Solids, vol. 65, no. 2-3, pp. 171-175, 2004.

[35] J. Miyawaki, M. Yudasaka, H. Imai et al., "In vivo magnetic resonance imaging of single-walled carbon nanohorns by labeling with magnetite nanoparticles," Advanced Materials, vol. 18, no. 8, pp. 1010-1014, 2006.

[36] Y. Li, E. J. Lee, and S. O. Cho, "Superhydrophobic coatings on curved surfaces featuring remarkable supporting force," Journal of Physical Chemistry C, vol. 111, no. 40, pp. 1481314817, 2007.

[37] R. N. Gedye, F. E. Smith, and K. C. Westaway, "The rapid synthesis of organic compounds in microwave ovens," Canadian Journal of Chemistry, vol. 66, no. 1, pp. 17-26, 1988.

[38] L. Perreux and A. Loupy, "A tentative rationalization of microwave effects in organic synthesis according to the reaction medium, and mechanistic considerations," Tetrahedron, vol. 57, no. 45, pp. 9199-9223, 2001.

[39] D. A. Lewis, J. D. Summers, T. C. Ward, and J. E. McGrath, "Accelerated imidization reactions using microwave radiation," Journal of Polymer Science A, vol. 30, no. 8, pp. 16471653, 1992.

[40] C. Shibata, T. Kashima, and K. Ohuchi, "Nonthermal influence of microwave power on chemical reactions," Japanese Journal of Applied Physics A, vol. 35, no. 1, pp. 316-319, 1996.

[41] J. M. Planeix, N. Coustel, B. Coq et al., "Application of carbon nanotubes as supports in heterogeneous catalysis," Journal of the American Chemical Society, vol. 116, no. 17, pp. 7935-7936, 1994.

[42] S. Banerjee and S. S. Wong, "Synthesis and characterization of carbon nanotube-nanocrystal heterostructures," Nano Letters, vol. 2, no. 3, pp. 195-200, 2002.

[43] K. Woan, G. Pyrgiotakis, and W. Sigmund, "Photocatalytic carbon-nanotube- $\mathrm{TiO}_{2}$ composites," Advanced Materials, vol. 21, no. 21, pp. 2233-2239, 2009.

[44] A. B. Hungria, B. H. Juarez, C. Klinke, H. Weller, and P. A. Midgley, "3-D Characterization of CdSe nanoparticles attached to carbon nanotubes," Nano Research, vol. 1, no. 1, pp. 89-97, 2008.

[45] T. Kishi, T. Hashishin, and J. Tamaki, "Tin oxide nanoparticles deposited inside multiwalled carbon nanotubes for sensor application," in Proceedings of the 214th ECS Meeting on H1Nanostructure and Function of Fullerenes, Carbon Nanotubes, and Related Materials, The Electrochemical Society, Honolulu, Hawaii, USA, October 2008, Abstract no. 2702.

[46] G. G. Wildgoose, C. E. Banks, and R. G. Compton, "Metal nanoparticles and related materials supported on carbon nanotubes: methods and applications," Small, vol. 2, no. 2, pp. 182-193, 2006.

[47] V. Georgakilas, D. Gournis, V. Tzitzios, L. Pasquato, D. M. Guldi, and M. Prato, "Decorating carbon nanotubes with metal or semiconductor nanoparticles," Journal of Materials Chemistry, vol. 17, no. 26, pp. 2679-2694, 2007.

[48] J. M. Tang, K. Jensen, M. Waje et al., "High performance hydrogen fuel cells with ultralow Pt loading carbon nanotube thin film catalysts," Journal of Physical Chemistry C, vol. 111, no. 48, pp. 17901-17904, 2007.

[49] L. Qu and L. Dai, "Substrate-enhanced electroless deposition of metal nanoparticles on carbon nanotubes," Journal of the American Chemical Society, vol. 127, no. 31, pp. 10806-10807, 2005. 
[50] W. Q. Han and A. Zettl, "Coating single-walled carbon nanotubes with tin oxide," Nano Letters, vol. 3, no. 5, pp. 681-683, 2003.

[51] K. S. Coleman, S. R. Bailey, S. Fogden, and M. L. H. Green, "Functionalization of single-walled carbon nanotubes via the bingel reaction," Journal of the American Chemical Society, vol. 125, no. 29, pp. 8722-8723, 2003.

[52] H. B. Chu, J. Y. Wang, L. Ding et al., "Decoration of gold nanoparticles on surface-grown single-walled carbon nanotubes for detection of every nanotube by surface-enhanced raman spectroscopy," Journal of the American Chemical Society, vol. 131, no. 40, pp. 4310-14316, 2009.

[53] J. Li, S. Tang, L. Lu, and H. C. Zeng, "Preparation of nanocomposites of metals, metal oxides, and carbon nanotubes via selfassembly," Journal of the American Chemical Society, vol. 129, no. 30, pp. 9401-9409, 2007.

[54] D. Wang, Z. C. Li, and L. Chen, "Templated synthesis of singlewalled carbon nanotube and metal nanoparticle assemblies in solution," Journal of the American Chemical Society, vol. 128, no. 47, pp. 15078-15079, 2006.

[55] J. Huang, T. Kunitake, and S. Y. Onoue, "A facile route to a highly stabilized hierarchical hybrid of titania nanotube and gold nanoparticle," Chemical Communications, vol. 2004, no. 8, pp. 1008-1009, 2004.

[56] L. Liu, T. Wang, J. Li et al., "Self-assembly of gold nanoparticles to carbon nanotubes using a thiol-terminated pyrene as interlinker," Chemical Physics Letters, vol. 367, no. 5-6, pp. 747-752, 2003.

[57] T. Smorodin, U. Beierlein, and J. P. Kotthaus, "Contacting gold nanoparticles with carbon nanotubes by self-assembly," Nanotechnology, vol. 16, no. 8, pp. 1123-1125, 2005.

[58] R. Zhang, M. Hummelgård, and H. Olin, "Simple and efficient gold nanoparticles deposition on carbon nanotubes with controllable particle sizes," Materials Science and Engineering B, vol. 158, no. 1-3, pp. 48-52, 2009.

[59] A. Loupy, D. Monteux, A. Petit, J. M. Aizpurua, E. Domínguez, and C. Palomo, "Towards the rehabilitation of the Leuckart reductive amination reaction using microwave technology," Tetrahedron Letters, vol. 37, no. 45, pp. 8177-8180, 1996.

[60] R. Laurent, A. Laporterie, J. Dubac, J. Berlan, S. Lefeuvre, and M. Audhuy, "Specific activation by microwaves: myth or reality?" Journal of Organic Chemistry, vol. 57, no. 26, pp. 7099-7102, 1992.

[61] J. Y. Kim, K. H. Kim, S. H. Park, and K. B. Kim, "Microwavepolyol synthesis of nanocrystalline ruthenium oxide nanoparticles on carbon nanotubes for electrochemical capacitors," Electrochimica Acta, vol. 55, no. 27, pp. 8056-8061, 2010.

[62] H. Chuncheng, D. Yipeng, and L. Li, "Microwave-assisted heating method for the decoration of carbon nanotubes with zinc sulfide nanoparticles," Journal of Dispersion Science and Technology, vol. 30, no. 5, pp. 691-693, 2009.

[63] K. Ghosh, M. Kumar, H. Wang, T. Maruyama, and Y. Ando, "Facile decoration of platinum nanoparticles on carbonnitride nanotubes via microwave-assisted chemical reduction and their optimization for field-emission application," Journal of Physical Chemistry C, vol. 114, no. 11, pp. 5107-5112, 2010.

[64] P. Goncalo, C. Roussel, J. M. Mélot, and J. Vébrel, "Contribution of microwaves in organic synthesis: statement of a methodology for the microwave-induced preparation of benzofuran-2(3H)-one and its comparison with classical heating," Journal of the Chemical Society, Perkin Transactions 2, no. 10, pp. 2111-2115, 1999.

[65] S. Motshekga, S. K. Pillai, and S. S. Ray, "Conventional wet impregnation versus microwave-assisted synthesis of
$\mathrm{SnO}_{2} / \mathrm{CNT}$ composites," Journal of Nanoparticle Research, vol. 13, no. 3, pp. 1093-1099, 2010.

[66] Z. Gan, X. Zheng, D. Wei et al., "One-pot synthesis of onedimensional array Pt nanoparticles on carbon nanotubes via a facile microwave polyol method," Superlattices and Microstructures, vol. 47, no. 6, pp. 705-709, 2010.

[67] H. Wu, P. Cao, W. Li, N. Ni, L. Zhu, and X. Zhang, "Microwave-assisted synthesis and magnetic properties of sizecontrolled CoNi/MWCNT nanocomposites," Journal of Alloys and Compounds, vol. 509, no. 4, pp. 1261-1265, 2011.

[68] X. Li, W. X. Chen, J. Zhao, W. Xing, and Z. D. Xu, "Microwave polyol synthesis of $\mathrm{Pt} / \mathrm{CNTs}$ catalysts: effects of $\mathrm{pH}$ on particle size and electrocatalytic activity for methanol electrooxidization," Carbon, vol. 43, no. 10, pp. 2168-2174, 2005.

[69] C. Liang, W. Xia, H. Soltani-Ahmadi, O. Schlüter, R. A. Fischer, and M. Muhler, "The two-step chemical vapor deposition of $\mathrm{Pd}($ allyl $) \mathrm{Cp}$ as an atom-efficient route to synthesize highly dispersed palladium nanoparticles on carbon nanofibers," Chemical Communications, vol. 2, no. 2, pp. 282284, 2005.

[70] M. Pang, C. Li, L. Ding et al., "Microwave-assisted preparation of $\mathrm{Mo}_{2} \mathrm{C} / \mathrm{CNTs}$ nanocomposites as efficient electrocatalyst supports for oxygen reduction reaction," Industrial and Engineering Chemistry Research, vol. 49, no. 9, pp. 4169-4174, 2010.

[71] M. Meyyappan, Carbon Nanotubes: Science and Applications, CRC, Boca Raton, Fla, USA, 2005.

[72] M. R. Pederson and J. Q. Broughton, "Nanocapillarity in fullerene tubules," Physical Review Letters, vol. 69, no. 18, pp. 2689-2692, 1992.

[73] A. C. Dillon, K. M. Jones, T. A. Bekkedahl, C. H. Kiang, D. S. Bethune, and M. J. Heben, "Storage of hydrogen in singlewalled carbon nanotubes," Nature, vol. 386, pp. 377-379, 1997.

[74] S. J. Park and S. Y. Lee, "Hydrogen storage behaviors of platinum-supported multi-walled carbon nanotubes," International Journal of Hydrogen Energy, vol. 35, no. 23, pp. 1304813054, 2010.

[75] C. C. Yang, Y. J. Li, and W. H. Chen, "Electrochemical hydrogen storage behavior of single-walled carbon nanotubes (SWCNTs) coated with Ni nanoparticles," International Journal of Hydrogen Energy, vol. 35, no. 6, pp. 2336-2343, 2010.

[76] C. Xu, J. Sun, and L. Gao, "Synthesis of multiwalled carbon nanotubes that are both filled and coated by $\mathrm{SnO}_{2}$ nanoparticles and their high performance in lithium-ion batteries," Journal of Physical Chemistry C, vol. 113, no. 47, pp. 2050920513, 2009.

[77] Z. Wang, G. Chen, and D. Xia, "Coating of multi-walled carbon nanotube with $\mathrm{SnO}_{2}$ films of controlled thickness and its application for Li-ion battery," Journal of Power Sources, vol. 184, no. 2, pp. 432-436, 2008.

[78] X. Zhao, W. Li, L. Jiang et al., "Multi-wall carbon nanotube supported Pt-Sn nanoparticles as an anode catalyst for the direct ethanol fuel cell," Carbon, vol. 42, no. 15, pp. 3263-3265, 2004.

[79] H. Zhang, J. Qiu, C. Liang et al., "A novel approach to $\mathrm{Co} / \mathrm{CNTs}$ catalyst via chemical vapor deposition of organometallic compounds," Catalysis Letters, vol. 101, no. 3-4, pp. 211-214, 2005.

[80] J. P. Tessonnier, L. Pesant, G. Ehret, M. J. Ledoux, and C. Pham-Huu, "Pd nanoparticles introduced inside multi-walled carbon nanotubes for selective hydrogenation of cinnamaldehyde into hydrocinnamaldehyde," Applied Catalysis A, vol. 288, no. 1-2, pp. 203-210, 2005. 
[81] X. R. Ye, Y. Lin, and C. M. Wai, "Decorating catalytic palladium nanoparticles on carbon nanotubes in supercritical carbon dioxide," Chemical Communications, vol. 9, no. 5, pp. 642-643, 2003.

[82] T. Matsumoto, T. Komatsu, K. Arai et al., "Reduction of Pt usage in fuel cell electrocatalysts with carbon nanotube electrodes," Chemical Communications, no. 7, pp. 840-841, 2004.

[83] M. Sakthivel, A. Schlange, U. Kunz, and T. Turek, "Microwave assisted synthesis of surfactant stabilized platinum/carbon nanotube electrocatalysts for direct methanol fuel cell applications," Journal of Power Sources, vol. 195, no. 20, pp. 7083 7089, 2010.

[84] E. H. Espinosa, R. Ionescu, B. Chambon et al., "Hybrid metal oxide and multiwall carbon nanotube films for low temperature gas sensing," Sensors and Actuators, B, vol. 127, no. 1, pp. 137-142, 2007.

[85] Y. L. Liu, H. F. Yang, Y. Yang, Z. M. Liu, G. L. Shen, and R. Q. $\mathrm{Yu}$, "Gas sensing properties of tin dioxide coated onto multiwalled carbon nanotubes," Thin Solid Films, vol. 497, no. 1-2, pp. 355-360, 2006.

[86] C. Wongchoosuk, A. Wisitsoraat, D. Phokharatkul, A. Tuantranont, and T. Kerdcharoen, "Multi-walled carbon nanotubedoped tungsten oxide thin films for hydrogen gas sensing," Sensors, vol. 10, no. 8, pp. 7705-7715, 2010.

[87] Y. Lu, J. Li, J. Han et al., "Room temperature methane detection using palladium loaded single-walled carbon nanotube sensors," Chemical Physics Letters, vol. 391, no. 4-6, pp. 344348, 2004.

[88] Q. Shi, T. Peng, and J. Cheng, "A cholesterol biosensor based on cholesterol oxidase immobilized in a sol-gel on a platinumdecorated carbon nanotubes modified electrode," Chinese Journal of Analytical Chemistry, vol. 33, no. 3, pp. 329-332, 2005.

[89] S. Qiaocui, P. Tuzhi, Z. Yunu, and C. F. Yang, "An electrochemical biosensor with cholesterol oxidase/sol-gel film on a nanoplatinum/carbon nanotube electrode," Electroanalysis, vol. 17, no. 10, pp. 857-861, 2005.

[90] C. Dechakiatkrai, J. Chen, C. Lynam, S. Phanichphant, and G. G. Wallace, "Photocatalytic oxidation of methanol using titanium dioxide/single-walled carbon nanotube composite," Journal of the Electrochemical Society, vol. 154, no. 5, pp. A407A411, 2007.

[91] C. Liu, K. S. Kim, J. Baek et al., "Improved field emission properties of double-walled carbon nanotubes decorated with Ru nanoparticles," Carbon, vol. 47, no. 4, pp. 1158-1164, 2009.

[92] X. R. Ye, Y. Lin, C. Wang, M. H. Engelhard, Y. Wang, and C. M. Wai, "Supercritical fluid synthesis and characterization of catalytic metal nanoparticles on carbon nanotubes," Journal of Materials Chemistry, vol. 14, no. 5, pp. 908-913, 2004.

[93] X. R. Ye and J. B. Talbot, "Supercritical fluid attachment of catalytic metal nanoparticles onto carbon nanotubes," in Proceedings of the 229th ACS National Meeting: Abstracts of Papers, IEC, San Diego, Calif, USA, 2005.

[94] S. Hermans, J. Sloan, D. S. Shephard, B. F. G. Johnson, and M. L. H. Green, "Bimetallic nanoparticles aligned at the tips of carbon nanotubes," Chemical Communications, vol. 231, no. 3, pp. 276-277, 2002.

[95] W. Lu, X. Ma, N. Lun, and S. Wen, "Decoration of carbon nanotubes with gold nanoparticles for catalytic applications," in Proceedings of the Nanoengineered Assemblies and Advanced Micro/Nanosystems, pp. 75-80, San Francisco, Calif, USA, April 2004.

[96] Y. N. Zhu, T. Z. Peng, and J. P. Li, "Electrocatalytic oxidation of hydrogen peroxide at a glassy carbon electrode modified with platinum-decorated carbon nanotubes," Chemical Journal of Chinese Universities, vol. 25, no. 9, pp. 1637-1641, 2004.

[97] A. L. Ramaswamy, P. Kaste, A. W. Miziolek, B. Homan, S. Trevino, and M. A. O'Keefe, "Nanoenergetics weaponization and characterization technologies," in Defense Applications of Nanomaterials, vol. 891 of ACS Symposium Series, pp. 180197, American Chemical Society, 2005. 

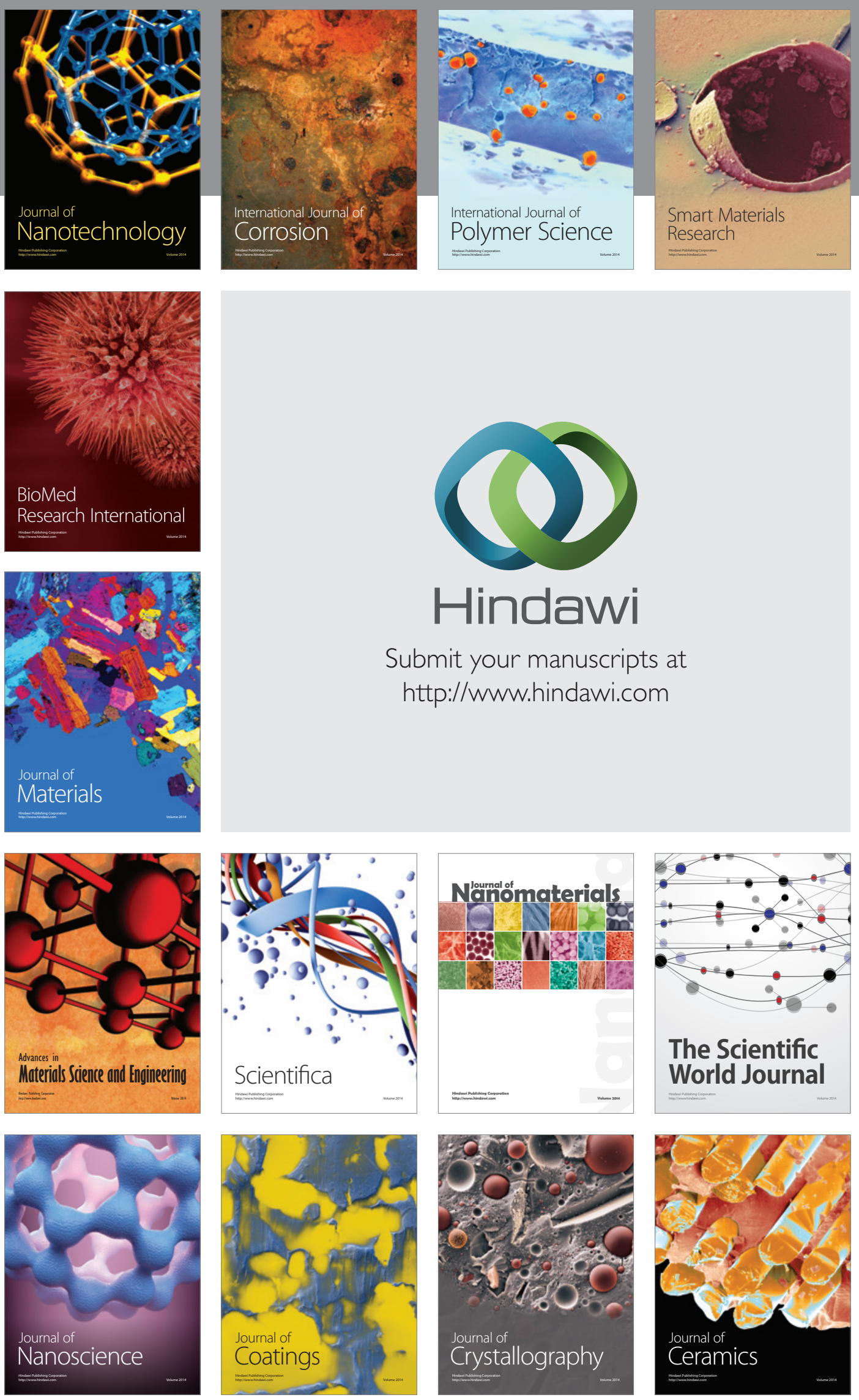

The Scientific World Journal

Submit your manuscripts at

http://www.hindawi.com

\section{World Journal}

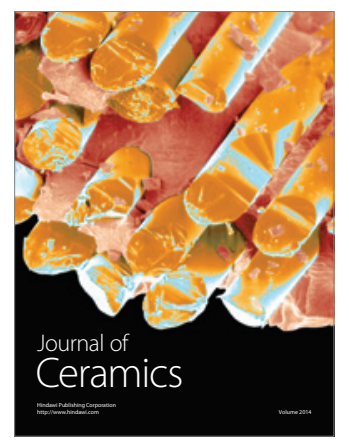

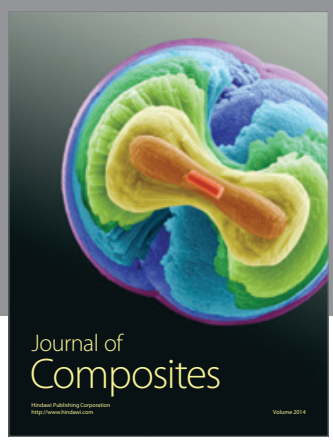
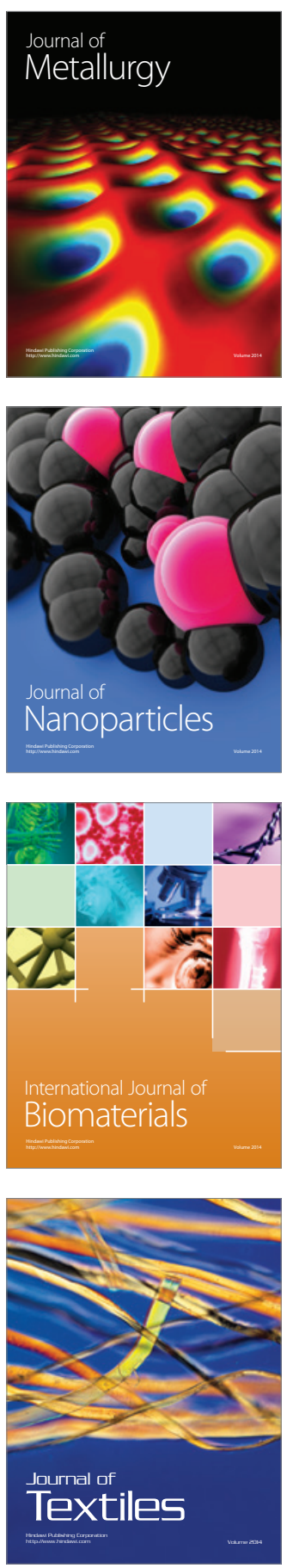